\title{
Palladium-Catalyzed Aerobic Homocoupling of Alkynes: Full Mech- anistic Characterization of a More Complex Oxidase-type Behavior
}

\author{
Alberto Toledo, ${ }^{\dagger}$ Ignacio Funes-Ardoiz, ${ }^{\dagger}$ Feliu Maseras $\stackrel{\dagger}{\dagger} \S_{*}$ and Ana C. Albéniz ${ }^{\dagger}, *$ \\ †IU CINQUIMA/Química Inorgánica. Universidad de Valladolid. 47071 Valladolid (Spain). \\ Institute of Chemical Research of Catalonia (ICIQ). The Barcelona Institute of Science and Technology. Avgda. Països \\ Catalans, 16, 43007 Tarragona (Spain). \\ $\S$ Departament de Química, Universitat Autònoma de Barcelona, 08193 Bellaterra (Spain).
}

\section{Supporting Information Placeholder}

\begin{abstract}
A combined experimental and computational approach has been used to shed light on the mechanism of the Pdcatalyzed oxidative homocoupling of alkynes using oxygen as oxidant. Mechanistic understanding is important because of the synthetically relevant direct involvement of oxygen in the oxidative coupling, and because of the presence of related processes as undesired side reactions in cross-coupling reactions involving terminal alkynes. A low-ligated $\left[\mathrm{Pd}\left(\mathrm{PPh}_{3}\right)(\right.$ alkyne) $]$ complex is key in the process and it can be conveniently generated from allylic palladium(II) complexes in the presence of a base or from Pd(I) allylic dimers as precatalysts. The catalytic coupling occurs by alkyne metalation to give an anionic $\left[\mathrm{Pd}\left(\mathrm{PPh}_{3}\right)(\text { alkynyl) }]^{-}\right.$complex that is then oxidized by oxygen. The interaction of oxygen occurs only on this electron rich $\operatorname{Pd}(0)$ anionic species and leads to a $\kappa^{2}$-peroxo palladium(II) singlet intermediate that undergoes subsequent protonolysis to a $\kappa^{1}$-hydroperoxide palladium(II) complex. The second alkyne metalation occurs on the $\mathrm{Pd}(\mathrm{II})$ hydroperoxo derivative, this ligand acting as an internal base, to give a bis(alkynyl)Pd(II) complex that evolves to the product by reductive elimination as the product-forming step. This reaction is an oxidase-type process that, in contrast to most Pd-catalyzed oxidative processes, occurs without separation of the substrate transformation and the catalyst oxidation, both processes being intertwined and dependent of one another.
\end{abstract}

\section{INTRODUCTION}

Selective aerobic oxidation of organic substrates is a key challenge in modern chemistry, and homogeneous Pdcatalyzed oxidation reactions are situated among the most promising and versatile strategies to achieve this goal. ${ }^{1}$ Effective transformations range from the classic alcohol oxidation, ${ }^{2}$ or Wacker and related processes, ${ }^{3}$ to oxidative carbonylation reactions, ${ }^{4}$ oxidative $\mathrm{C}-\mathrm{C}, \mathrm{C}-\mathrm{O}$, and $\mathrm{C}-\mathrm{N}$ coupling reactions with alkenes, ${ }^{3,5}$ and the emerging $\mathrm{C}-\mathrm{H}$ functionalization. ${ }^{6}$ The scope and utility of Pd-catalyzed aerobic oxidation reactions have expanded significantly in the last years thanks to the recent developments of efficient $\mathrm{O}_{2}$-coupled catalytic systems in the absence of cocatalytic and/or stoichiometric oxidants such as benzoquinone, $\mathrm{Ag}(\mathrm{I})$ or $\mathrm{Cu}(\mathrm{II})$ salts. ${ }^{7}$ Molecular oxygen is the ideal oxidant due to its availability and the production of environmentally safe reduction byproducts such as water and hydrogen peroxide (the latter, itself a commercially important chemical). The catalytic mechanism of these reactions where oxygen is the sole oxidant is believed to proceed through an "oxidase" style sequence, consisting of two half reactions in which substrate oxidation by $\mathrm{Pd}(\mathrm{II})$ is followed by aerobic oxidation of the reduced catalyst (Scheme 1, a). Several observations support this mechanistic proposal: i) Pd(II) is an effective stoichiometric oxidant for a variety of organic substrates, ii) molecular oxygen is thermodynamically capable of oxidizing reduced palladium under many conditions, and iii) the Pd catalyst commonly decomposes into Pd black during the reaction (via aggregation into Pd nanoparticles and/or bulk metallic Pd, Scheme 1, b), a result that implicates the presence of a $\operatorname{Pd}(0)$ intermediate in the catalytic cycle. The intrinsic instability of $\operatorname{Pd}(0)$ makes necessary to ensure an efficient reaction between dioxygen and the reduced palladium catalyst,${ }^{8}$ even if this reaction is not the turnover-limiting step of the catalytic mechanism.

Two main mechanisms have been proposed for the dioxygen-coupled oxidation of the catalyst: i) formation of a $\left(\kappa^{2}-\right.$ peroxo)palladium species by oxygenation of $\operatorname{Pd}(0)$ species (Scheme 1b, pathway A), and ii) direct reaction of molecular oxygen with a $\mathrm{Pd}(\mathrm{II})$ hydride intermediate (Scheme 1b, pathway B). ${ }^{9}$ The actual oxidation route is strongly dependent on the particular palladium complex and its specific set of ligands, and isolated complexes that illustrate both types of reactivity have been reported. Mechanistic studies have shown that pathway A (Scheme 1b) is more common. The formation of $\mathrm{Pd}(\mathrm{II}) \kappa^{2}$-peroxo complexes from $\left[\mathrm{Pd}\left(\mathrm{PR}_{3}\right)_{n}\right]$ and oxygen was studied in the 1960 's ${ }^{10}$ and recent results 
show that this is also possible for $\mathrm{N}$-donor ligands and $\mathrm{N}$ heterocyclic carbenes, ${ }^{11}$ as well as their protonation to give hydroperoxide derivatives. ${ }^{12}$ Even if a palladium hydrido complex is formed in the reaction, it has been found that reductive elimination of HX (the reverse reaction in pathway B, Scheme $1 \mathrm{~b}),{ }^{13}$ or a hydrogen abstraction in the hydride complex, ${ }^{14}$ can drive the oxidation process towards $\operatorname{Pd}(0)$ and the $\kappa^{2}$-peroxo complex. Nonetheless, some examples of pathway $\mathbf{B}$ have also been documented, ${ }^{15}$ and in some complexes both pathways are plausible. ${ }^{16}$ The study of the coordination of $\mathrm{O}_{2}$ to $\mathrm{Pd}(0)$ has also shown that the involvement of superoxide species is possible. ${ }^{17}$

Scheme 1. Representation of (a) a general Pd-oxidase type catalytic process and (b) proposed mechanisms for $\operatorname{Pd}(0)$ reoxidation with dioxygen.

a)
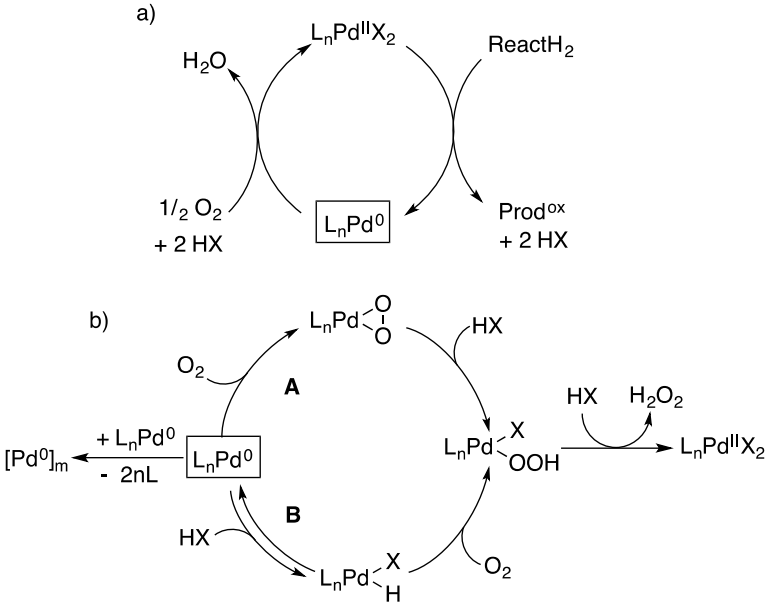

A formal oxidase-type reaction is the Pd-catalyzed oxidative homocoupling of terminal alkynes. The formation of diynes by oxidative $\mathrm{C}-\mathrm{C}$ coupling of alkynes in the presence of dioxygen has been known for a long time and it is catalyzed by copper compounds (the Glaser reaction), and also by a combination of palladium and copper complexes. ${ }^{18,19} \mathrm{~A}$ few examples of this reaction can be found in the literature where just $\mathrm{Pd}$ complexes as catalysts and dioxygen as oxidant are used. ${ }^{20}$ Besides its synthetic interest in the formation of polyynes, this reaction is also frequently observed as a competitive process in Sonogashira couplings. Although this is a familiar and apparently simple reaction, its accepted mechanism is just based on reasonable hypotheses due to the lack of detailed studies of the steps involved. Scheme 2 illustrates the commonly proposed mechanism, where a palladium(II) complex reacts sequentially with two alkyne molecules to give a cis-bisalkynyl palladium(II) complex that undergoes a reductive elimination leading to the diyne product and $\operatorname{Pd}(0)$ that needs to be reoxidized. . $^{18,20 b, 21}$

To address these questions, computational chemistry has been demonstrated to be a valuable methodology. ${ }^{22}$ Particularly, Pd-catalyzed cross-coupling reactions have been extensively discussed in the literature, clarifying the role of the different factors, such as ligand effects or oxidation states, in the reactivity. ${ }^{23}$ Recently, the development of oxidative version of catalytic couplings has prompted us to expand the classic mechanisms to systems in which an oxidant plays an important role. ${ }^{19,24}$
Scheme 2. General proposed mechanism for the Pdcatalyzed homocoupling of alkynes.

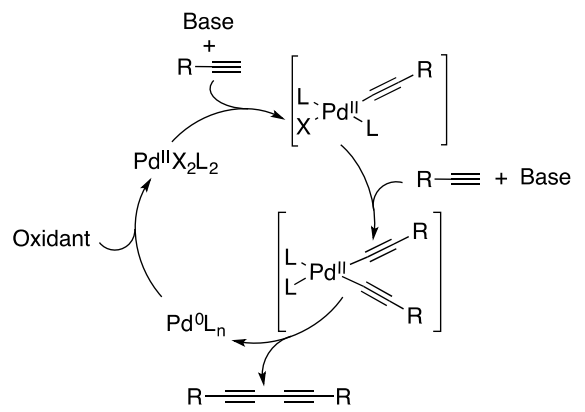

Our former work on the study of the reactions of alkynyl organometallics with palladium(II) allyl complexes showed that the latter are suitable catalyst precursors in the transformation of $\mathrm{C}(\mathrm{sp})$ substrates. ${ }^{25}$ The reductive elimination of allyl-alkynyl in [Pd(allyl)(alkynyl)L] complexes is slow and therefore, the allylic group is not prone to participate in a $\mathrm{C}$ $\mathrm{C}$ bond forming step. Its expected role is that of either a spectator ligand (a good donor and small ligand, which fixes a cis geometry), or a fragment that can facilitate the generation of the active species. Indeed, we found that $\left[\mathrm{Pd}(\right.$ allyl $\left.) \mathrm{Cl}\left(\mathrm{PPh}_{3}\right)\right]$ showed a good activity in the formation of 1,3-diynes from alkynes. We report here the combined experimental and computational mechanistic studies on this system, which shows some interesting and unexpected features. We have analyzed in detail the formation of the active low ligated " $\mathrm{PdPPh}_{3} \mathrm{~L}$ " species from the precatalyst, and we have also found that the reactions with the alkyne (i.e. deprotonation and formation of the Pd-alkynyl bonds) occur before and after the actual oxidation with dioxygen. This is different from the typical and well-accepted oxidase behavior, since the oxidation of the catalyst cannot be separated from the substrate oxidation. The need of a "naked" anionic $\mathrm{Pd}(0)$ complex to coordinate the $\mathrm{O}_{2}$ enabling the oxidation process is key in this case and might have a role in other aerobic oxidative couplings of hydrocarbons.

\section{RESULTS AND DISCUSSION}

Aerobic synthesis of 1,3-diynes from alkynes catalyzed by $\left[\mathbf{P d}\left(\eta^{3}\right.\right.$-allyl) $\left.\mathbf{C l}\left(\mathbf{P P h}_{3}\right)\right]$. The alkyne homocoupling reaction was tested using 1-ethynylcyclohexene as reactant, sodium acetate and $5 \mathrm{~mol} \%$ of complex $\left[\mathrm{Pd}\left(\eta^{3}\right.\right.$-allyl $\left.) \mathrm{Cl}\left(\mathrm{PPh}_{3}\right)\right](\mathbf{1})$ as the catalyst in a mixture of acetone/water at room temperature in the air. ${ }^{1} \mathrm{H}$ NMR was used to monitor the course of the reaction, since the alkene region of 1-ethynylcyclohexene in ${ }^{1} \mathrm{H}$ NMR does not overlap with any other reagent signals and allows an easy follow up of the reaction by this technique. We were glad to observe the chemoselective formation of the dialkyne $\mathbf{2}$ and the absence of any byproduct (Eq. 1). A screening of reaction conditions (Table 1) revealed that a mixture water/acetone $(1: 1)$ and a $50 \%$ excess of sodium acetate as the base in the open air gave good results (entry 1, Table 1 and Eq. 1). Other solvents can also be used as long as the acetate salt is soluble in them (entries 5 and 6, Table 1). However, the solvent mixture and the base depicted in Eq. 1 are more convenient and environmentally friendly.

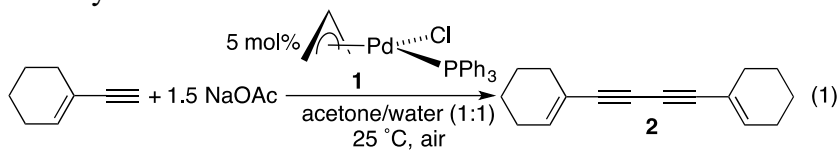


The diyne $\mathbf{2}$ is also formed in water but the reaction is less efficient (entry 3, Table 1). CsF can also be used as base (entry 7, Table 1) but amines like DBU are inefficient.

No trace of the dialkyne 2 was observed when the reaction was carried out in the absence of base, catalyst or oxidant. Although the base is necessary, it is worth noting that a substoichiometric amount of acetate is enough to perform the reaction (entry 8 , Table 1), and even the same amount as the catalyst ( $5 \mathrm{~mol} \%$ ) produces the formation of 2 although very slowly in this case (entry 9, Table 1). In order to probe the possibility of a radical-chain mechanism, we evaluated the reaction in the presence of the radical inhibitor galvinoxyl, and the formation of the dialkyne was essentially unaffected by the presence of this additive. We tested the recyclability of the catalyst solution and, after the reaction had finished, a second portion of alkyne and base was added. The catalyst was still active but the reaction conversion decreased significantly ( $17 \%$ of 2 in $22 \mathrm{~h}$ for the second addition).

The effect of the amount of oxidant $\left(\mathrm{O}_{2}\right)$ was evaluated by carrying out experiments in sealed tubes with identical shape in the optimized conditions. As mentioned before, the presence of oxygen is necessary (entry 10, Table 1) and a faster

Table 1. Synthesis of 2 catalyzed by complex 1 under different reaction conditions. ${ }^{\mathrm{a}}$

\begin{tabular}{|c|c|c|c|c|}
\hline Entry & Oxidant & Base $^{b}$ & Solvent ${ }^{\mathrm{c}}$ & $\begin{array}{l}\text { 2, \% Crude yield } \\
(3 \mathrm{~h} / 7 \mathrm{~h} / 22 \mathrm{~h})\end{array}$ \\
\hline 1 & air & $\mathrm{NaOAc}$ & $\mathrm{H}_{2} \mathrm{O} /$ Acetone & $66 / 83 / 100$ \\
\hline 2 & air & $\mathrm{NaOAc}$ & $\begin{array}{l}\mathrm{H}_{2} \mathrm{O} / \text { Acetone } \\
(1: 3)\end{array}$ & $29 / 39 / 90$ \\
\hline 3 & air & $\mathrm{NaOAc}$ & $\mathrm{H}_{2} \mathrm{O}$ & $55 / 61 / 77$ \\
\hline 4 & air & $\mathrm{NBu}_{4} \mathrm{OAc}$ & $\mathrm{H}_{2} \mathrm{O} /$ Acetone & $66 / 83 / 100$ \\
\hline 5 & air & $\mathrm{NBu}_{4} \mathrm{OAc}$ & Acetone & $79 / 98 / 100$ \\
\hline 6 & air & $\mathrm{NBu}_{4} \mathrm{OAc}$ & $\mathrm{CH}_{2} \mathrm{Cl}_{2}$ & $10 / 62 / 100$ \\
\hline 7 & air & $\mathrm{CsF}$ & $\mathrm{H}_{2} \mathrm{O} /$ Acetone & $42 / 77 / 100$ \\
\hline 8 & air & $\begin{array}{l}\mathrm{NaOAc} \\
(0.5)\end{array}$ & $\mathrm{H}_{2} \mathrm{O} /$ Acetone & $56 / 71 / 73$ \\
\hline 9 & air & $\begin{array}{l}\mathrm{NaOAc} \\
(0.05)\end{array}$ & $\mathrm{H}_{2} \mathrm{O} /$ Acetone & $6 / 8 / 49$ \\
\hline $10^{\mathrm{e}}$ & $\mathrm{N}_{2}$ & $\mathrm{NaOAc}$ & $\mathrm{H}_{2} \mathrm{O} /$ Acetone & $0 / 0 / 0$ \\
\hline $11^{\mathrm{e}}$ & air & $\mathrm{NaOAc}$ & $\mathrm{H}_{2} \mathrm{O} /$ Acetone & $37 / 67 / 100$ \\
\hline $12^{\mathrm{e}}$ & $\mathrm{O}_{2}$ & $\mathrm{NaOAc}$ & $\mathrm{H}_{2} \mathrm{O} /$ Acetone & $90 / 100 / 100$ \\
\hline $13^{e}$ & $\begin{array}{l}\text { air } \\
\text { +allyl } \\
\text { acetate }\end{array}$ & $\mathrm{NaOAc}$ & $\mathrm{H}_{2} \mathrm{O} /$ Acetone & $22 / 83 / 100$ \\
\hline
\end{tabular}

a) All the reactions were carried out using $0.85 \mathrm{mmol}$ of the alkyne at $25{ }^{\circ} \mathrm{C}$ with $5 \mathrm{~mol} \%$ of 1 in an open flask unless otherwise noted; total volume of solvent: $8 \mathrm{~mL}$. b) A molar ratio base/alkyne $=1.5$ was used, unless otherwise noted in parentheses. c) $\mathrm{H}_{2} \mathrm{O} /$ Acetone $=1 / 1(\mathrm{v} / \mathrm{v})$ unless otherwise noted. d) The reactions were chemoselective and the crude yields were determined by integration of the alkene resonances of the alkyne and 2 by ${ }^{1} \mathrm{H}$ NMR. e) The reactions were carried out in tightly closed flasks of the same shape and dimensions. reaction was observed when air was substituted by pure oxygen (entries 11 and 12, Table 1). However, not only the amount but also the diffusion rate of oxygen in the solution appeared to be very important in controlling the reaction rate. From the very first experiments, we realized that the use of different reaction vessels under otherwise identical conditions resulted in different reaction rates; therefore, to ensure comparable experiments, all the reactions in Table 1 were carried out in round bottomed flasks of the same shape and dimensions. Shorter reaction times were achieved by saturation of the solvent just slowly bubbling air or pure oxygen. The oxygen diffusion-controlled rate in aerobic Pd-catalyzed oxidations has been found and studied by Steinhoff and Stahl. ${ }^{26}$ The low solubility of oxygen in water may be one of the reasons of the reduced yields of the reaction in this solvent (entry 3, Table 1). The addition of an excess of allyl acetate, a $\operatorname{Pd}(0)$ reoxidant by oxidative addition sometimes used in similar reactions, did not have a beneficial effect (entry 13, Table 1). ${ }^{27}$ With the optimized conditions in hand, the activity of other palladium complexes was evaluated (Table 2).

Table 2. Synthesis of 2 catalyzed by different palladium complexes in the conditions of Eq. 1. ${ }^{\mathrm{a}}$

\begin{tabular}{|c|c|c|c|}
\hline Entry & Catalyst & $\begin{array}{l}\text { Additive } \\
\text { (Add/Pd mol ratio) }\end{array}$ & $\begin{array}{l}\% \text { Conversion } \\
(3 \mathrm{~h} / 7 \mathrm{~h} / 22 \mathrm{~h})^{\mathrm{b}}\end{array}$ \\
\hline 1 & 1 & & $66 / 83 / 100$ \\
\hline 2 & $\mathrm{Pd} / \mathrm{C}$ & & $0 / 0 / 0$ \\
\hline 3 & $\mathrm{Pd}(\mathrm{OAc})_{2}$ & & $0 / 6 / 10$ \\
\hline 4 & $\mathrm{Pd}(\mathrm{OAc})_{2}$ & $\mathrm{PPh}_{3}(2)$ & $0 / 25 / 58^{c}$ \\
\hline 5 & $\mathrm{Pd}(\mathrm{OAc})_{2}$ & allyl acetate (5) & $5 / 5 / 10$ \\
\hline 6 & $\mathrm{Pd}(\mathrm{OAc})_{2}$ & $\begin{array}{l}\mathrm{PPh}_{3}(2)+ \\
\text { allyl acetate (1) }\end{array}$ & $35 / 50 / 64$ \\
\hline 7 & {$\left[\mathrm{Pd}_{2}(\mathrm{dba})_{3}\right]$} & & $0 / 0 / 0$ \\
\hline 8 & {$\left[\mathrm{Pd}_{2}(\mathrm{dba})_{3}\right]$} & $\mathrm{PPh}_{3}(2)$ & $4 / 21 / 79$ \\
\hline 9 & {$\left[\mathrm{Pd}_{2}(\mathrm{dba})_{3}\right]$} & $\begin{array}{l}\mathrm{PPh}_{3}(2)+ \\
\text { allyl acetate }(10)\end{array}$ & $25 / 84 / 100^{d}$ \\
\hline 10 & {$\left[\mathrm{Pd}\left(\mathrm{PPh}_{3}\right)_{2}(\mathrm{MA})\right]^{\mathrm{e}}$} & & $0 / 0 / 0$ \\
\hline 11 & {$\left[\mathrm{Pd}\left(\mathrm{PPh}_{3}\right)_{4}\right]$} & & $19 / 20 / 41$ \\
\hline 12 & {$[\mathrm{Pd}(\mu-\mathrm{Cl})(\text { allyl })]_{2}$} & & $0 / 0 / 11$ \\
\hline 13 & {$[\mathrm{Pd}(\mu-\mathrm{Cl})(\text { allyl })]_{2}$} & $\mathrm{P}(o-\mathrm{Tol})_{3}(2)$ & $57 / 75 / 100$ \\
\hline 14 & {$[\mathrm{Pd}(\mu-\mathrm{Cl})(\text { allyl })]_{2}$} & $\mathrm{P}\left(p-\mathrm{OMeC}_{6} \mathrm{H}_{4}\right)_{3}(2)$ & $30 / 79 / 100$ \\
\hline 15 & {$[\mathrm{Pd}(\mu-\mathrm{Cl})(\text { allyl })]_{2}$} & $\mathrm{P}\left(\mathrm{C}_{6} \mathrm{~F}_{5}\right)_{3}(2)$ & $0 / 0 / 0$ \\
\hline 16 & {$\left[\mathrm{Pd}(\right.$ allyl $\left.) \mathrm{Cl}\left(\mathrm{AsPh}_{3}\right)\right]$} & & $0 / 28 / 68$ \\
\hline 17 & {$\left[\mathrm{PdCl}_{2}(\mathrm{dppe})\right]$} & & $0 / 0 / 0^{\mathrm{f}}$ \\
\hline
\end{tabular}

a) Reaction conditions: $0.85 \mathrm{mmol}$ of alkyne at $25^{\circ} \mathrm{C}$ in $8 \mathrm{~mL}$ of acetone/water $=1: 1(\mathrm{v} / \mathrm{v}) ; 5 \mathrm{~mol} \%$ of $\mathrm{Pd} ; \mathrm{NaOAc}$ (molar ratio $\mathrm{NaOAc} /$ alkyne $=1.5$ ) in the air (see Eq. 1). b) The reactions were chemoselective, and conversion equals to crude yield, except when noted; conversions were determined by integration of the alkene signals of the cyclohexenyl group in ${ }^{1} \mathrm{H}$ NMR. c) $16 \%$ of other unidentified byproducts. d) The excess of allyl acetate led to $33 \%$ of byproducts resulting from the 2:2 cross-coupling of the alkyne and the allylic fragment (ref. 25a). e) $\mathrm{MA}=$ maleic anhydride. f) $45 \%$ conversion in 8 days. 
The use of other common Pd catalytic precursors such as $\mathrm{Pd}(\mathrm{OAc})_{2}$ or $\mathrm{Pd} / \mathrm{C}$ resulted in no reaction or traces of the dialkyne (entries 2 and 3, Table 2). The same behavior was found with $\left[\mathrm{Pd}(\mu-\mathrm{Cl})\left(\eta^{3} \text {-allyl) }\right]_{2}\right.$ (entry 12 , Table 2 ) or some common $\operatorname{Pd}(0)$ complexes (entries 7 and 10, Table 2). The amount of $\mathrm{PPh}_{3}$ is crucial and the best reaction results were achieved when just one phosphine per Pd was added (entry 8 , Table 1$)$. The reaction was very slow with $\left[\mathrm{Pd}\left(\mathrm{PPh}_{3}\right)_{4}\right]$ and the increase in yield at a late stage might be associated to oxidation of some of the $\mathrm{PPh}_{3}$ present (entry 11, Table 2). Complex $\mathbf{1}$ is clearly the best catalyst, used either preformed or generated in situ from a different palladium precursor and a combination of $\mathrm{PPh}_{3}$ and an allylic source (entries 6 and 9, Table 2). Other arylphosphines with electron-donating groups have a similar efficiency than $\mathrm{PPh}_{3}$, but the less donor $\mathrm{P}\left(\mathrm{C}_{6} \mathrm{~F}_{5}\right)_{3}$ resulted in no catalysis (entries 13-15, Table 2). Substitution of the $\mathrm{PPh}_{3}$ for a more labile ligand such as $\mathrm{AsPh}_{3}$ led to a worse conversion (entry 16, Table 2). $\left[\mathrm{PdCl}_{2}\right.$ (dppe)] gave no reaction in $22 \mathrm{~h}$ (entry 17, Table 2) and only after a very long reaction time ( 8 days) $45 \%$ yield of 2 was obtained.

The homocoupling reaction of a range of alkynes was explored using complex $\mathbf{1}$ as the best catalyst precursor in the conditions of Table 1, entry 1. As can be seen in Scheme 3, phenylacetylene and aromatic alkynes with electron-donating groups or weak electron-withdrawing groups were found to be good substrates for the formation of 1, 3-diynes. This system also allows the homocoupling of non-aromatic terminal alkynes. In contrast, those acetylenes with electronwithdrawing groups afforded the cyclotrimerization products along with $\left(\mathrm{R}=p-\mathrm{CF}_{3}-\mathrm{C}_{6} \mathrm{H}_{4}\right.$, Scheme 3$)$ or instead of the desired dialkynes $\left(\mathrm{R}=\mathrm{CO}_{2} \mathrm{Me}\right)$. The cyclotrimerization of this type of alkynes to give substituted arenes induced by palladium complexes is well known, and both $\operatorname{Pd}(0),{ }^{28}$ and $\mathrm{Pd}(\mathrm{II})$ complexes can catalyze this reaction. ${ }^{29}$

Scheme 3. Aerobic synthesis of 1,3-diynes catalyzed by complex 1.

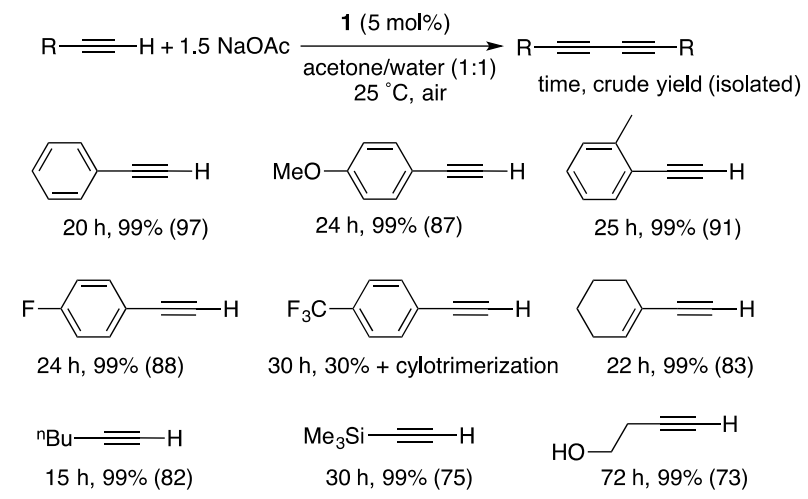

Kinetic experiments. Reactions leading to the formation of the diyne 2 were monitored by ${ }^{1} \mathrm{H}$ NMR. In order to have reliable and reproducible conditions and ensure enough oxygen solubility, we performed the reactions in acetone as solvent (instead of the mixture water-acetone), and $\mathrm{NBu}_{4} \mathrm{OAc}$ as a soluble base (Table 1, entry 5). In these conditions using an NMR tube equipped with a J. Young PTFE valve and saturated oxygenated acetone under $1 \mathrm{~atm}$ of oxygen, clean spectra were obtained and the formation of $\mathbf{2}$ was monitored at $298 \mathrm{~K}$ (Eq. 2).

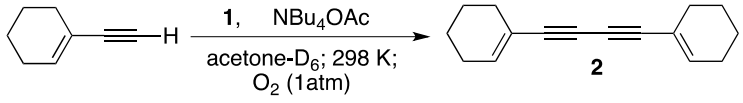

As it is collected in Table 1 (entries 10-12) we could observe a qualitative dependence of the concentration of oxygen (air vs. $\mathrm{O}_{2}$ ). The gas-liquid mass transport limitation was again demonstrated comparing the conversion when the operation technique was changed: after $3 \mathrm{~h}$ in the conditions of Eq. 2, under 1 atm of $\mathrm{O}_{2}$, only $46 \%$ yield of 2 was observed in an NMR tube vs $90 \%$ in a Schlenk flask with continuous stirring. ${ }^{26}$ To avoid the rate-limiting mass-transfer of oxygen gas into the solution, the kinetic reactions were carried out in a range of low concentrations of the catalyst (0.59-2.70 mM). The solubility of oxygen in acetone under these conditions is close to $12 \mathrm{mM}^{30}$

Figure 1 (a) shows the monitorization results for the formation of dialkyne 2 , up to $75 \%$ conversion. The reaction time course shows a faster reaction in the first $30 \mathrm{~min}$ followed by a decrease of rate of approximately threefold: $\mathrm{k}_{\mathrm{obs}}=$ $0.149 \mathrm{~min}^{-1}$ from 0 to $20 \%$ conversion vs $\mathrm{k}_{\mathrm{obs}}=0.046 \mathrm{~min}^{-1}$ in the range $20-40 \%$ conversion). This behaviour can be attributed to a product inhibition in the reaction and we corroborated this effect by addition of dialkyne $2(0.39 \mathrm{mg}, 2.63$ $\mathrm{mM}$, equivalent to a $11 \%$ of conversion) when a $9 \%$ of conversion was achieved. We could observe the rate becoming again three times slower, since $\mathrm{k}_{\text {obs }}=0.168 \mathrm{~min}^{-1}$ up to $9 \%$ conversion (before dialkyne addition) and $\mathrm{k}_{\mathrm{obs}}=0.058$ $\min ^{-1}$ between $10-20 \%$ conversion (Figure $1, \mathrm{~b}$ ). It has to be noted that an induction period of up to $10-15$ min was often observed in the experimental follow up (Figure $1 \mathrm{~b}$, blue plot) indicating that a slow generation of the active catalytic species was taking place (see below).
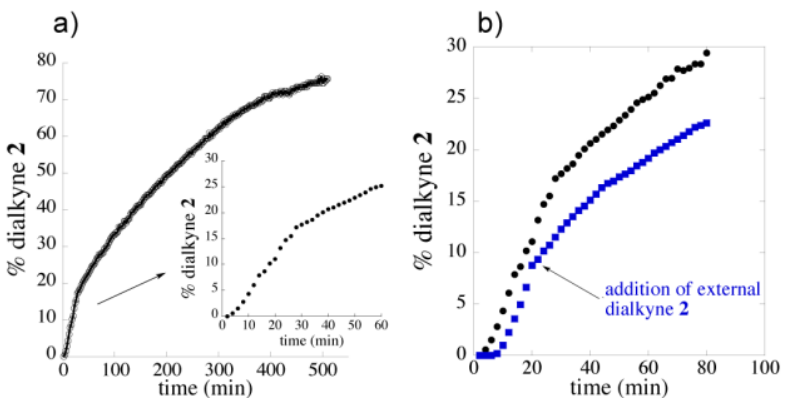

Figure 1. a) Time course for the formation of $\mathbf{2}$ catalyzed by complex 1 in the conditions of Eq. $2([\mathrm{Pd}]=1.19 \mathrm{mM})$ and expansion for the first $60 \mathrm{~min}$ of the reaction. b) Comparison of time course for the formation of $\mathbf{2}$ in the experiment shown in (a) (black) to that when external dialkyne $\mathbf{2}$ was added (blue).

We assessed the dependence of the rate on the concentration of the reagents using the initial rates method and in each experiment the reaction was monitored at least to $15 \%$ conversion to 2 . The rate of product formation as a function of Pd concentration was measured over a concentration range of $0.59-2.70 \mathrm{mM}$, under the reaction conditions of Eq. 2. The homocoupling of the alkyne showed a first order dependence on catalyst $1(1.13 \pm 0.08$, Figure 2 , a). We next assessed the kinetic order in acetate and alkyne proceeding in a similar manner. The order in alkyne was determined by varying the concentration of 1-ethynylcyclohexene from 12.15 to $48.6 \mathrm{mM}$ (Figure 2, b). Under these conditions, the reaction showed approximately a zero order dependence $(0.17 \pm 0.05)$. 
a)

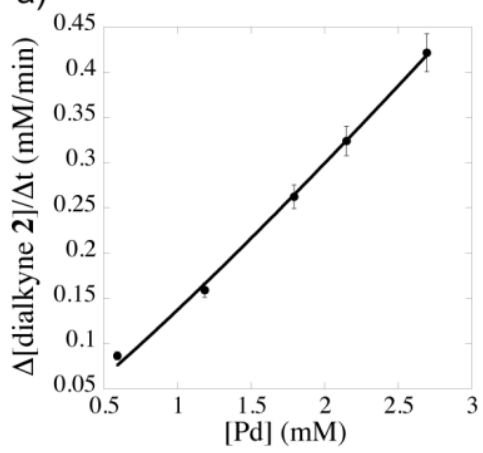

b)

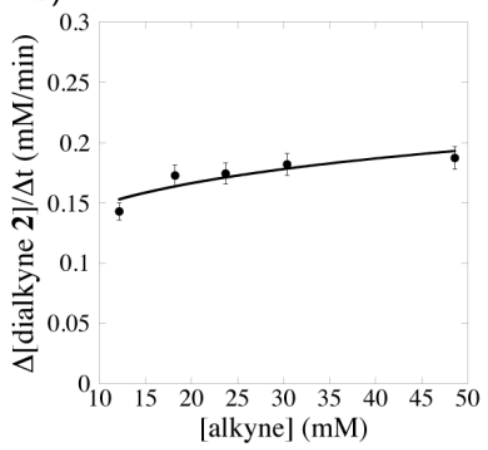

c)

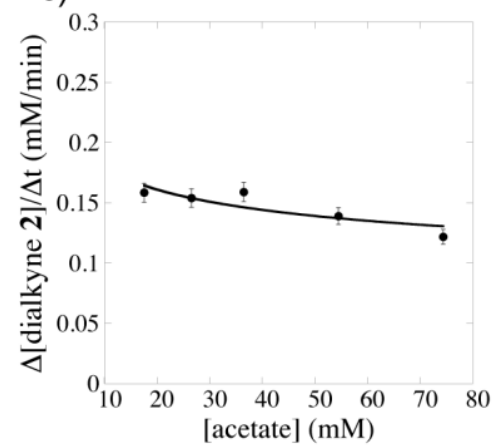

Figure 2. Rate dependence of the reaction depicted in Eq. 2 upon the concentration of: (a) complex $\mathbf{1}([\mathrm{NBu} 4 \mathrm{OAc}]=36.48 \mathrm{mM},[1-$ ethynylcyclohexene $]=23.7 \mathrm{mM},[1]=0.59-2.70 \mathrm{mM})$; (b) the alkyne $([1$-ethynylcyclohexene $]=12.15-48.6 \mathrm{mM},[\mathrm{NBu} 4 \mathrm{OAc}]=36.48$ $\mathrm{mM},[1]=1.19 \mathrm{mM})$ and $(\mathrm{c})$ the base $([\mathrm{NBu} 4 \mathrm{OAc}]=17.53-74.38 \mathrm{mM},[1$-ethynylcyclohexene $]=23.7 \mathrm{mM},[1]=1.19 \mathrm{mM})$.

The order in acetate (Figure 2, c) was determined by varying the concentration of tetrabutylammonium acetate from 17.53 to $74.38 \mathrm{mM}$. Under these conditions, the reaction showed approximately a zero order dependence on acetate $(0.18 \pm$ 0.16). The kinetic isotope effect (KIE) was determined by comparing the initial reaction rate of $\mathrm{RC} \equiv \mathrm{CH}$ to that of $\mathrm{RC} \equiv \mathrm{CD}$ in separate experiments. A KIE $\left(\mathrm{k}_{\mathrm{H}} / \mathrm{k}_{\mathrm{D}}\right)$ of $1.97 \pm$ 0.01 was obtained from these experiments. The presence of a KIE invokes the importance of the cleavage of $\mathrm{C}-\mathrm{H}$ bond, but the value is not large enough to ensure the $\mathrm{C}-\mathrm{H}$ activation is the rate-limiting step. ${ }^{31}$ This KIE value could fit well in one of the scenarios nicely collected by Simmons and Hartwig, ${ }^{32}$ in which the cleavage of the $\mathrm{C}-\mathrm{H}$ bond is involved before the rate-limiting step. The zero order dependence in alkyne, first order in catalyst and the strong dependence on the oxygen concentration point to the oxidation as the rate determine step (see below).

Reactions of $\left[\mathrm{Pd}\left(\eta^{3}\right.\right.$-allyl $\left.) \mathrm{Cl}\left(\mathrm{PPh}_{3}\right)\right]$ under conditions relevant to the catalysis: Formation of the active species. The reactions of complex 1 with the reagents used in the oxidative homocoupling were monitored, in acetone- $\mathrm{D}_{6}$ or $\mathrm{CDCl}_{3}$ at variable temperature by ${ }^{1} \mathrm{H}$ and ${ }^{31} \mathrm{P} \mathrm{NMR}$, in order to detect new species that could play a role in the catalytic reaction. All the experiments were carried out in the air.

The addition of $\mathbf{1}$ to a solution of an equimolar amount of $\mathrm{NBu}_{4} \mathrm{OAc}$ in $\mathrm{CDCl}_{3}$ at room temperature led to the transformation of $50 \%$ of the starting allylic complex into several species (Eq. 3). The substitution of acetate for chloride led to the formation of complex $3(23 \%)$. Allyl acetate was present as well, which is necessarily accompanied by the formation of $\operatorname{Pd}(0)$ compounds. These species comproportionate with the more abundant $\mathrm{Pd}(\mathrm{II})$ allylic complex 1 to give the $\mathrm{Pd}(\mathrm{I})$ dimer $5(25 \%)$ in a very efficient way since no other significative ${ }^{31} \mathrm{P}$ NMR signals corresponding to decomposition species were observed. ${ }^{33,34}$ When the same reaction was carried out in acetone- $\mathrm{D}_{6}$ in analogous conditions, unreacted 1, $5(46 \%)$ and allyl acetate were formed but 3 was not observed in this case. The dissociation of acetate in the more polar and better coordinating acetone probably induces the decomposition of 3 leading to a higher amount of $\operatorname{Pd}(0)$ species and allyl acetate that, in turn, increase the amount of 5 detected.

When the reaction depicted in Eq. 3 was carried out at $243 \mathrm{~K}$ in $\mathrm{CDCl}_{3}$ in the presence of an equimolar amount of 1ethynylcyclohexene the formation of complex $\left[\operatorname{Pd}\left(\eta^{3}-\right.\right.$ $\left.\left.\mathrm{C}_{3} \mathrm{H}_{5}\right)(\mathrm{C} \equiv \mathrm{CR})\left(\mathrm{PPh}_{3}\right)\right](\mathrm{R}=1$-cyclohexenyl, 4a) was observed

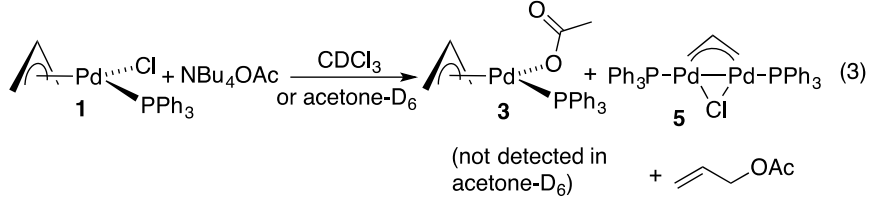

mixed with complex 3 and the starting material 1. The equilibrium can be driven to the complete formation of $\mathbf{4}$ if a tenfold excess of alkyne and acetate is used (Eq. 4). In this reaction $\left(\mathrm{R}={ }^{\mathrm{n}} \mathrm{Bu}\right)$ we first observed the ligand exchange between chloride and acetate resulting in $\mathbf{3}$ and the gradual formation of 4 . After $14 \mathrm{~h}$ at $243 \mathrm{~K}$, the $\sigma$-alkynyl palladium complex $4 \mathbf{b}$ was the only palladium complex present in the reaction. The formation of the diyne product was not observed.

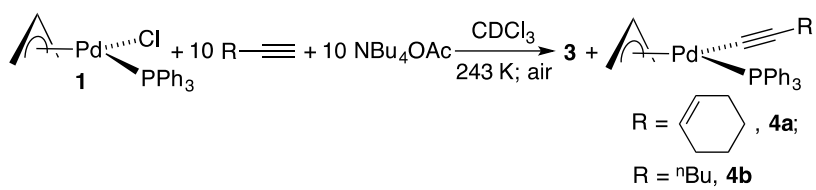

Complexes $\mathbf{4 a}, \mathbf{b}$ were prepared before in our group by transmetalation of an alkynyl group from tin to palladium. ${ }^{25}$ However, in this case the alkynyl palladium complex is detected and characterized by direct reaction of an alkyne and a base. This is the proposed route for the formation of the Pd-C(sp) bond in the Sonogashira couplings but, surprisingly, there are very few examples of such a process leading to well characterized palladium alkynyls without the assistance of an extra metal cocatalyst. ${ }^{35}$

The reaction was also monitored in acetone- $\mathrm{D}_{6}$ at $243 \mathrm{~K}$ (Scheme 4). As shown in Figure 3, after $3 \mathrm{~h}$ at $243 \mathrm{~K}$, the solution contained $\mathbf{4 a}$. The mixture did not change significantly until the temperature was raised to $298 \mathrm{~K}$, where $\mathbf{4 a}$ gradually disappeared and a new allylic Pd complex forms, which was identified as $\left[\mathrm{Pd}_{2}\left(\eta^{3}-\mathrm{C}_{3} \mathrm{H}_{5}\right)(\mu-\mathrm{C} \equiv \mathrm{CR})\left(\mathrm{PPh}_{3}\right)_{2}\right](7$, $\mathrm{R}=1$-cyclohexenyl). ${ }^{36}$ Some allyl acetate was also observed which reflects the occurrence of the decomposition of the allylic $\operatorname{Pd}(\mathrm{II})$ compounds to $\operatorname{Pd}(0)$, the reactant species in the formation of the $\operatorname{Pd}(\mathrm{I})$ complex 7. The formation of dialkyne 2 was also observed. Eventually, the slow disappearance of 7 (hours) also occurred. Although the acetate complex 3 was not detected in acetone- $\mathrm{D}_{6}$, its presence in the reaction media cannot be ruled out. In an independent experiment 3 was generated in acetone from complex 1 and AgOAc. The addition of 1-ethynylcyclohexene led to the formation of $4 \mathbf{a}$ and 
Scheme 4. Reactions of complex 1 with the alkyne in the presence of base at variable temperature.

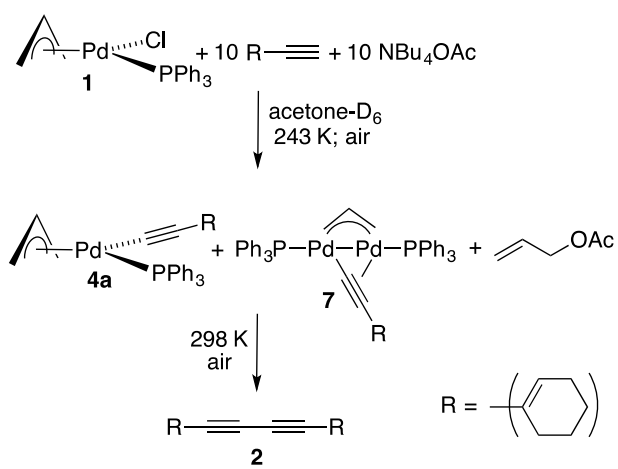

b)

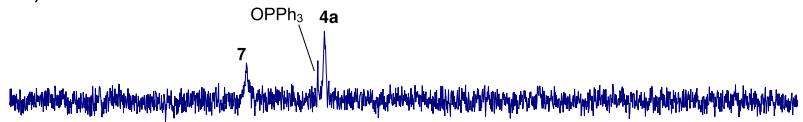

a)
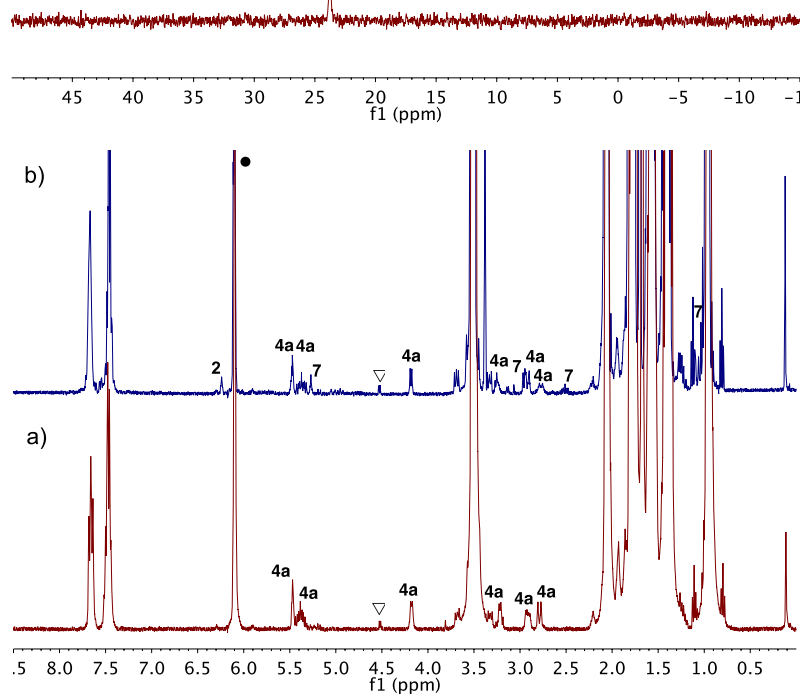

Figure $3 .{ }^{31} \mathrm{P}$ (top) and ${ }^{1} \mathrm{H}$ NMR (bottom) spectra of the mixture of 1 and tenfold molar amount of 1-ethynylcyclohexene and $\mathrm{NBu}_{4} \mathrm{OAc}$ in acetone-D 6 after a) $3 \mathrm{~h}$ at $243 \mathrm{~K}$; b) $1 \mathrm{~h}$ at $293 \mathrm{~K}$. $\boldsymbol{\bullet}=$ alkyne; $\nabla=$ allyl acetate.

the $\mathrm{Pd}(\mathrm{I})$ derivatives 5, $\left[\mathrm{Pd}_{2}\left(\eta^{3}-\mathrm{C}_{3} \mathrm{H}_{5}\right)(\mu-\mathrm{OAc})\left(\mathrm{PPh}_{3}\right)_{2}\right]$ and $\mathbf{7}$ as minor species.

The identity of the $\operatorname{Pd}(\mathrm{I})$ complexes detected in our experiments was supported by the independent synthesis of complex $5,{ }^{37}$ and the exchange of the chloro bridge for alkynyl to give 7, as shown in Eq. 5. The acetate complex 6 was observed when 5 was reacted with just $\mathrm{NBu}_{4} \mathrm{OAc}$ in acetone$\mathrm{D}_{6}$. Complex 7 was also formed by transmetalation of the alkynyl group from tributylalkynyltin to $\mathbf{5}$, in a similar procedure that the one we reported before for the $\mathrm{Pd}(\mathrm{II})$ complexes $4^{25}$

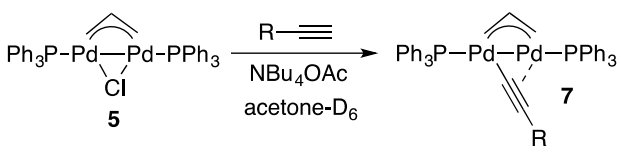

All the results obtained in the experiments described above allow to draw a complete picture of the reactions that take place on complex 1 under catalytic conditions (Scheme 5). Three main processes occur: i) Deprotonation of the alkyne and coordination of the alkynyl fragment to $\mathrm{Pd}(\mathrm{II})$ to give 4, ii) decomposition of the $\mathrm{Pd}(\mathrm{II})$ allylic species by nucleophilic attack of acetate to the allylic fragment to give allyl acetate and $\operatorname{Pd}(0)$ species ${ }^{38}$ iii) trap of the $\operatorname{Pd}(0)$ species by comproportionation with $\mathrm{Pd}(\mathrm{II})$ complexes to give $\mathrm{Pd}(\mathrm{I})$ dimeric allylic derivatives (5-7). The two latter reactions are favored in acetone rather than in non-coordinating and less polar chlorinated solvents. Only complexes $\mathbf{4}$ and $\mathbf{7}$ were detected in the catalytic mixtures at room temperature. However, the formation of the dialkyne is never observed from complex 4 in the monitorization experiments described above. Usually, the product builds up along with the formation of byproducts of the reduction of $\mathrm{Pd}(\mathrm{II})$ allylic complexes such as allyl acetate. This strongly points to a $\operatorname{Pd}(0)$ derivative as the actual active species in the reaction, which is coordinatively unsaturated since just one phosphine per palladium is the optimal metal to ligand ratio. Nonetheless, complex $\mathbf{4}$ is not a dead end since it can revert to complex 1 by protonation, as we have independently tested, and it can reenter the route to $\operatorname{Pd}(0)$ via the putative cationic $\left[\operatorname{Pd}\left(\eta^{3}-\mathrm{C}_{3} \mathrm{H}_{5}\right)(\pi-\right.$ $\left.\mathrm{C} \equiv \mathrm{CR})\left(\mathrm{PPh}_{3}\right)\right] \mathrm{X}$ in Scheme 5 .

Scheme 5. Formation of the active $\operatorname{Pd}(0)$ species from precatalyst 1.

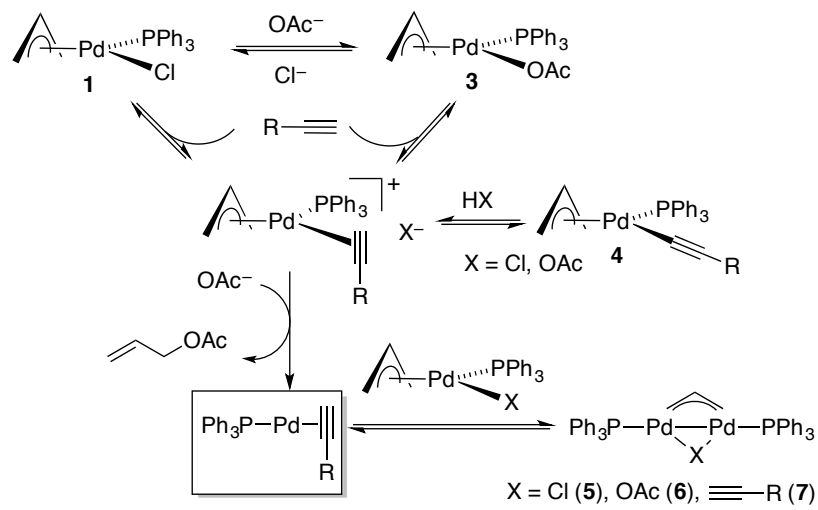

The disproportionation of the dimeric Pd(I) complex 7 can regenerate the $\operatorname{Pd}(0)$ complex, so 7 is acting as a reservoir of palladium active species. If this is the case, complex 7 (or a suitable $\operatorname{Pd}(\mathrm{I})$ precursor) should be active in the aerobic homocoupling of alkynes. We analyzed the activity of complex 5, which forms 7 in the presence of the alkyne and the base (Eq. 5), in the same conditions used for 1 as catalyst (Table 1, entry 1). As shown in Table $3, \mathbf{5}$ is an active catalyst but a double Pd:alkyne ratio is needed to achieve a similar yield to that obtained using $\mathbf{1}$ as catalyst (same mol\% amount of both complexes, entries 1 and 3, Table 3). Thus, 5 (or 7 ) can generate the $\operatorname{Pd}(0)$ active species needed for catalysis at a rate which is dependent on the ease of disproportionation of the complex and, overall, is less efficient that the generation of the same species from 1. Interestingly, the aerobic homocoupling reaction occurs in the absence of base with complex 5 (entry 4, Table 3 ) but the dialkyne is not formed with 1 unless a base is used. Therefore, the main and indispensable role of the acetate salt must be the formation of the catalytic active $\operatorname{Pd}(0)$ species from 1, whereas 5 can produce those species by a disproportionation reaction. 
When a base is absent just half of the Pd contained in $\mathbf{5}$ can be transformed in $\operatorname{Pd}(0)$ and the remaining $\mathrm{Pd}(\mathrm{II})$ derivatives do not decompose; thus, the differences in the crude yields observed for entries 2 and 4 (Table 3) can be interpreted as a result of two experiments with different amount of catalyst.

In recent years, the involvement of $\operatorname{Pd}(\mathrm{I})$ complexes in catalytically relevant coupling processes has attracted a lot of attention. ${ }^{39-44}$ They may open up new mechanistic alternatives to the common operating routes. However, in most cases they play a role of a source of reactive $\operatorname{Pd}(0)$ species, as we believe it is the case here. ${ }^{45}$ The disproportionation of $\operatorname{Pd}(\mathrm{I})$ allylic derivatives as a function of the nature of the allylic fragment and the ligands involved has been studied in detail. $^{37}$

Table 3. Synthesis of 2 catalyzed by the Pd(I) complex 5.

\begin{tabular}{llll}
\hline Entry & {$[\mathrm{Pd}]$} & Base & $\begin{array}{l}\text { Conversion, \% } \\
(3 \mathrm{~h} / 7 \mathrm{~h} / 22 \mathrm{~h})^{\mathrm{b}}\end{array}$ \\
\hline 1 & $\mathbf{1}(5 \mathrm{~mol} \%)$ & $\mathrm{NaOAc}$ & $66 / 83 / 100$ \\
2 & $\mathbf{5}(2.5 \mathrm{~mol} \%)$ & $\mathrm{NaOAc}$ & $41 / 71 / 75$ \\
3 & $\mathbf{5}(5 \mathrm{~mol} \%)$ & $\mathrm{NaOAc}$ & $55 / 88 / 100$ \\
4 & $\mathbf{5}(2.5 \mathrm{~mol} \%)$ & - & $5 / 23 / 44$ \\
\hline
\end{tabular}

a) All the reactions were carried out using $0.85 \mathrm{mmol}$ of the alkyne at $25{ }^{\circ} \mathrm{C}$ in $8 \mathrm{~mL}$ of acetone/water $=1: 1(\mathrm{v} / \mathrm{v})$ with $\mathrm{NaOAc}($ molar ratio NaOAc/alkyne $=1.5$ ) in the air. The reactions were chemoselective and conversion equals to crude yield. b) The reactions were chemoselective and the crude yields were determined by integration of the alkene resonances of the alkyne and 2 by ${ }^{1} \mathrm{H}$ NMR.

Our experiments stubbornly pointed to a $\operatorname{Pd}(0)$ complex as the active catalyst that initiates the reaction. However, when looking at the literature, all the proposals for the Pdcatalyzed oxidative homocoupling of alkynes involve two consecutive metalations of an alkynyl group on a $\mathrm{Pd}(\mathrm{II})$ complex, although there is no detailed study of these reactions (Scheme 2). We tried to detect a cis-bisalkynyl palladium(II) complex that would be formed after a second alkyne metalation on $\mathbf{4}$, but we did not observe this intermediate in any monitorization experiment of the reaction. Neither such a complex nor the formation of the dialkyne product $\mathbf{2}$ were observed when we added four equivalents of 1cyclohexenylethynyl lithium to a solution of $\left[\mathrm{Pd}\left(\eta^{3}-\mathrm{C}_{3} \mathrm{H}_{5}\right)(\mu-\right.$ $\mathrm{Cl}]_{2}$ (See Scheme S1 in the Supporting information). Cisbisalkynyl palladium(II) complexes are extremely rare but complex 9 has been reported and characterized by reaction of $\left[\mathrm{PdCl}_{2}(\mathrm{dppe})\right]$ with either an alkyne in $\mathrm{NH}_{3}(1)$ or the alkynyl lithium derivative. ${ }^{46}$ As shown in Eq. 6, complex 9 led to the diyne 2 as the major product when we monitored its slow decomposition in acetone- $\mathrm{D}_{6}(90 \%$ after $13 \mathrm{~h}$ at $283 \mathrm{~K}$ and 6 $\mathrm{h}$ at room temperature). Despite the possibility of reaching this complex of by double metalation on $\mathrm{Pd}(\mathrm{II})$ and the fact that the reductive elimination is feasible, $\left[\mathrm{PdCl}_{2}(\mathrm{dppe})\right]$ is extremely slow and not a competitive catalyst for the homocoupling of terminal alkynes (entry 17, Table 2).

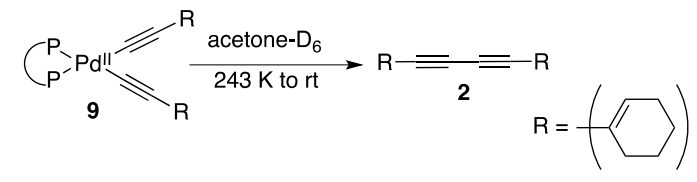

Computational studies. The experimental results reported above suggest a complex mechanism where a $\operatorname{Pd}(0)$ complex acts as catalyst, but cannot characterize all possible intermediates and have no access to transition states. Density functional theory (DFT) calculations were undertaken to gather more information about the detailed mechanism and energetics of the reaction. Ethynylbenzene was used as alkyne for all the calculations. Free energies in solution (acetone) were obtained using the B3LYP-D3 functional, ${ }^{47,48}$ and a triple- $\zeta$ basis set plus complemented with diffusion and polarization shells. ${ }^{49}$ Full computational details are supplied in the Supporting Information. A data set of all computational results is available in the ioChem-BD repository. ${ }^{50} \mathrm{We}$ label the species characterized only computationally with the prefix c. The computed thermodynamics of the overall coupling reaction are favorable, as expected, and the reaction $2 \mathrm{HC} \equiv \mathrm{CPh}+$ $\mathrm{O}_{2} \rightarrow \mathrm{PhC} \equiv \mathrm{C}-\mathrm{C} \equiv \mathrm{CPh}+\mathrm{H}_{2} \mathrm{O}_{2}$, is exergonic by $23.0 \mathrm{kcal} / \mathrm{mol}$. We analyzed first the equilibria in the precatalytic process described in Scheme 5 above. The computational results are summarized in the free energy profile in Figure 4. The activation of complex 1 starts with the exergonic $(2.8 \mathrm{kcal} / \mathrm{mol})$ displacement of the chloride ligand by acetate, yielding intermediate 3, also observed experimentally. We will use this intermediate $\mathbf{3}$ as origin of energies. From this point, two possibilities were considered: a neutral pathway (in blue) and a cationic pathway (in green). The highest free energy in Figure 4 is $24.2 \mathrm{kcal} / \mathrm{mol}$ (for TS-c3-c4) and the lowest free energy point is $-1.6 \mathrm{kcal} / \mathrm{mol}$ (for intermediate 7). This means that all intermediates shown in Figure 4 are accessible in the experimental conditions. Complex 4, among the most stable ones $(0.4 \mathrm{kcal} / \mathrm{mol})$ according to the calculation, was detected and characterized during the NMR monitorization of the reaction. Complex $\mathbf{c 4}$, postulated above as catalytically active because of the $\operatorname{Pd}(0)$ oxidation state and its available coordination site, is also accessible at $10.0 \mathrm{kcal} / \mathrm{mol}$. We also explored other pathways for the formation of the $\operatorname{Pd}(0)$ species, but all of them were similar in energy (see Table S8). The dimeric intermediate 7, at $-1.6 \mathrm{kcal} / \mathrm{mol}$, also experimentally detected, is accessible through comproprotionation of $\mathbf{c} \mathbf{4}$ and the more abundant species $\mathbf{4}$.

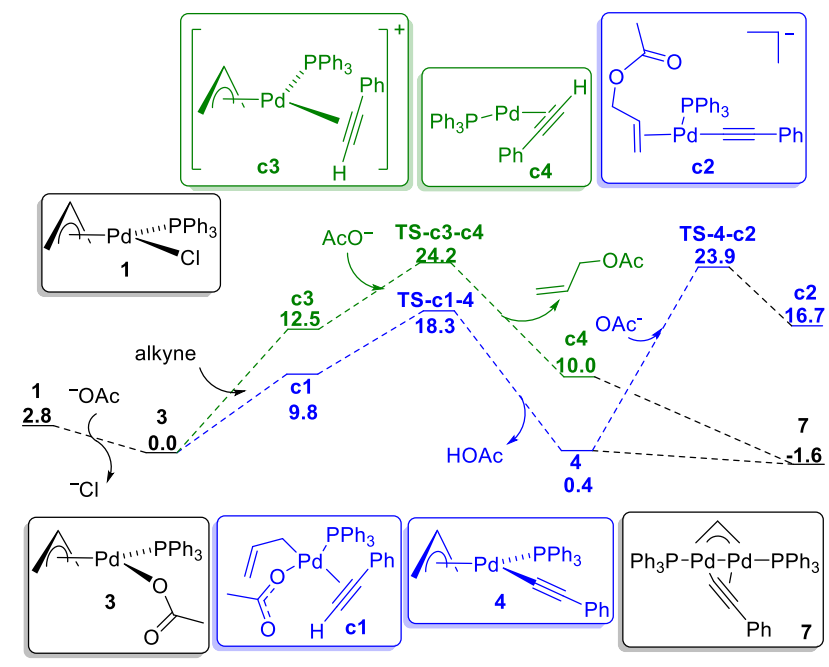

Figure 4. Free energy pathways of the precatalyst evolution and the formation of the experimentally observed intermediates. Energies in $\mathrm{kcal} / \mathrm{mol}$ referred to $\mathbf{3}$. 


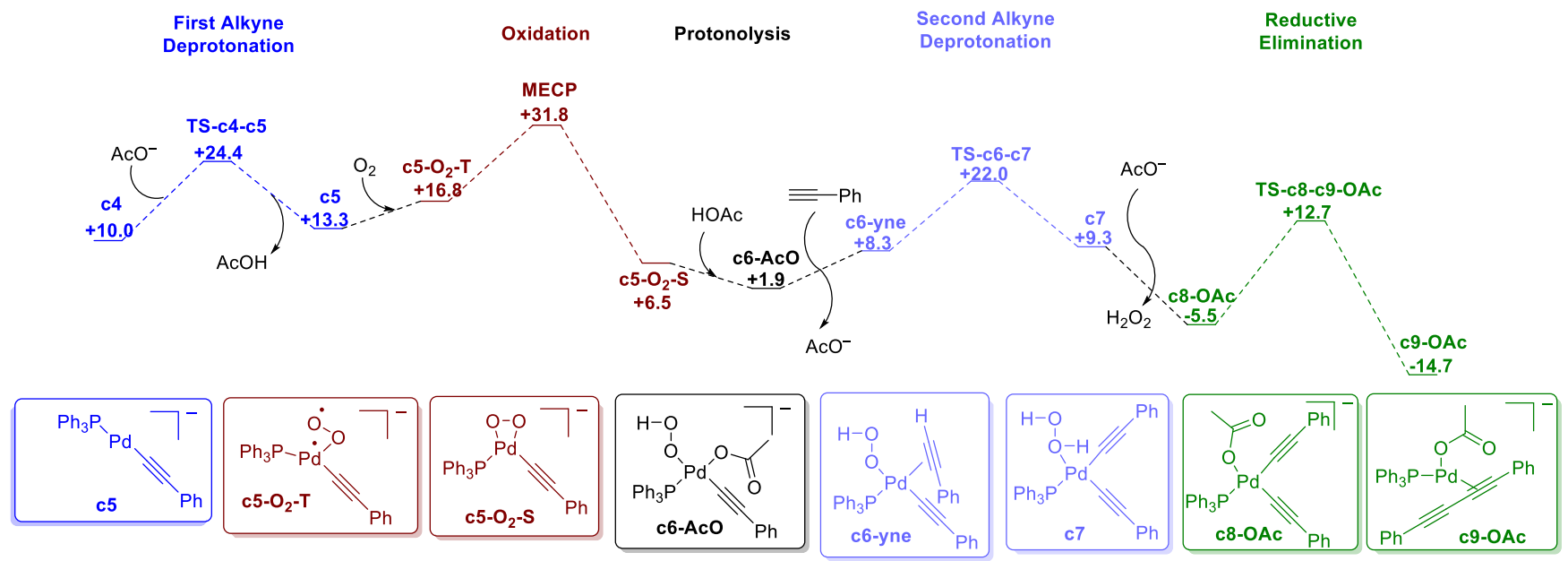

Figure 5. Free Energy profile for the oxidative homocoupling of alkynes starting with the in situ generated Pd(0) active species c4. Energies in $\mathrm{kcal} / \mathrm{mol}$ referred to 3 .

The DFT studies on the precatalytic species fit perfectly with the experimental data, where the detected intermediates by NMR $(3,4,7)$ are the lowest in energy, and with our proposal of 7 as a plausible off-cycle resting state. The catalytically active species c4 does not contain the allyl ligand, which is thus absent from the catalytic cycle. The role of the allyl group is nevertheless fundamental in the equilibria depicted in Figure 4, allowing the formation of the $\operatorname{Pd}(0)$ complex through its reductive coupling with acetate.

We then focused on the mechanism of the catalytic cycle. Figure 5 shows the energy profile obtained. The computed mechanism can be divided in five steps: first alkyne deprotonation, $\mathrm{Pd}$ oxidation, protonolysis of the $\mathrm{Pd}-\mathrm{O}$ bond, second alkyne deprotonation and reductive elimination. We initially explored the oxidation of the $\operatorname{Pd}(0)$ complex $\mathbf{c} 4$ by direct interaction with oxygen. All attempts at finding a starting point where $\mathrm{O}_{2}$ (in its triplet ground state) coordinates directly to the metal in $\mathbf{c} \mathbf{4}$ failed, leading to the release of free $\mathrm{O}_{2}$. In contrast, c4 reacts smoothly through TS-c4-c5 (at 24.4 $\mathrm{kcal} / \mathrm{mol}$ ) with an acetate anion to deprotonate the coordinated alkyne, leading to complex c5. Both intramolecular and intermolecular routes are feasible for this step, being the transition state for the external deprotonation just $1 \mathrm{kcal} / \mathrm{mol}$ lower in energy (see Figure S39 for the internal deprotonation). An alternative route for the reaction between complex c4 and alkyne, starting with oxidative addition was also considered, and found to be less efficient (see figure S40).

Remarkably, triplet molecular oxygen is able to coordinate to the anionic complex c5. Its coordination results in the superoxo Pd(I) complex c5-O2-T (Figure 6, left). The observed O$\mathrm{O}(1.270 \AA)$ and Pd-O (2.346 $\AA$ and $3.137 \AA)$ bond distances in the optimized structure, and the spin densities in oxygen centers $(0.81$ and 0.74$)$ and $\mathrm{Pd}(0.38)$ confirm the superoxo character of the species (Figure 6 , left). ${ }^{11 b, 17 b}$ This different behavior with respect to oxygen of the neutral (c4) and anionic (c5) complexes points towards the need of an electron rich $\operatorname{Pd}(0)$ center for the reaction to take place. The presence of anionic nucleophilic $\operatorname{Pd}(0)$ intermediates has been also proposed for the oxidative addition of aryl halides. ${ }^{51}$

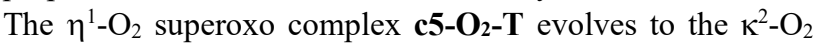

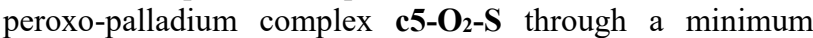
energy crossing point structure (MECP). The MECP is necessary for the crossing from the triplet to the singlet spin

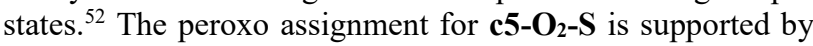

the computed O-O (1.421 $\AA)$ and Pd-O (2.036 $\AA$ and 2.017 $\AA$ ) bond distances in the optimized structure (Figure S44, supporting information). The MECP structure has a free energy of $31.8 \mathrm{kcal} / \mathrm{mol}$, which is the highest energy of the full free energy profile. The structure is shown in Figure 6, right. The arrangement around $\mathrm{Pd}$ is similar to that of $\mathbf{c 5 - \mathbf { O } _ { 2 } -}$ $\mathbf{T}$ differing in a lengthening of the $\mathrm{O}-\mathrm{O}$ bond from 1.270 to $1.350 \AA$, and a shortening of the Pd-O bonds from 2.346 to $1.957 \AA$ and 3.137 to $2.564 \AA$. The energy of the MECP can be mildly reduced to $29.6 \mathrm{kcal} / \mathrm{mol}$ if the ion pair interaction with $\mathrm{NMe}_{4}{ }^{+}$is considered (see Figure S41).

Intermediate $\mathbf{c 5 -}-\mathbf{O}_{2}-\mathbf{S}$ undergoes two low-barrier processes that lead sequentially to c6-OAc and c6-yne. Protonolysis of a $\mathrm{Pd}-\mathrm{O}$ bond of the $\kappa^{2}-\mathrm{O}_{2}$ peroxo ligand by an external acetic acid leads to c6-OAc, containing a hydroperoxo and an acetate ligand, in a process similar to those reported by Stahl and co-workers. ${ }^{12,13 a}$ The acetate ligand is then replaced by the second alkyne, resulting in complex c6-yne.

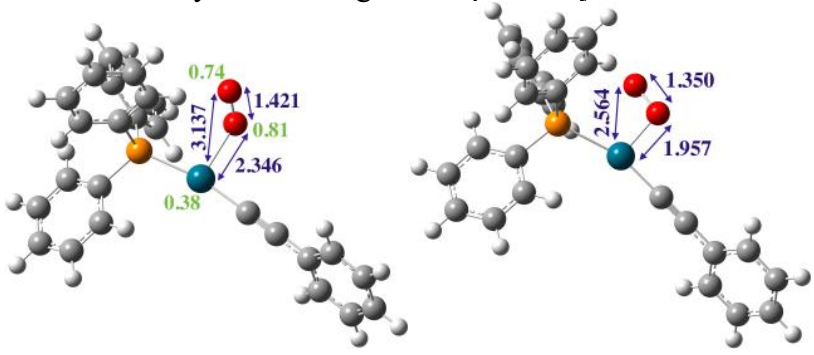

Figure 6. Optimized structures of the superoxo intermediate c5O2-T (left) and the MECP (right) including relevant bond lengths in $\AA$ (blue) and spin densities for the intermediate (green).

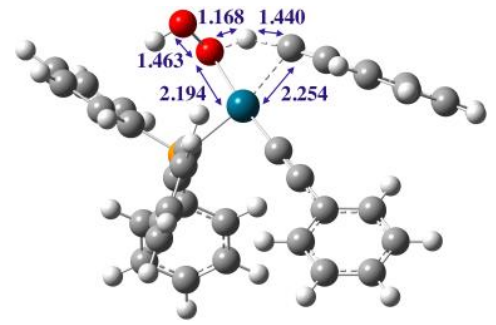

Figure 7. Optimized structure of TS-c6-c7. Relevant bond distances, in $\AA$, are highlighted. 
The next step is also formally simple: the hydroperoxo group deprotonates the coordinated alkyne, resulting in complex c7. The transition state TS-c6-c7 has a relatively high energy of $22.0 \mathrm{kcal} / \mathrm{mol}$, and it is shown in Figure 7. The C-H cleavage assisted by a coordinated oxygen byproduct has few precedents, such as the deprotonation assisted by a peroxo group, ${ }^{17 \mathrm{~b}}$ and the hydroperoxide here is another representative example. The reduction of oxygen requires a concomitant proton transfer, and this is not only a thermodynamic advantage but also a kinetic one when, while coordinated to palladium, it acts as an intramolecular base in reactions that need a proton abstraction (i.e. oxidative couplings with $\mathrm{C}-\mathrm{H}$ activation).

Species c7 is a $\mathrm{Pd}(\mathrm{II})$ complex with two alkynyl ligands. Direct reductive elimination from this neutral species goes to a transition state with an overall barrier of $24.1 \mathrm{kcal} / \mathrm{mol}$ (see Figure S43). In contrast, the anionic complex c8-OAc, resulting from the replacement of hydrogen peroxide by acetate, can easily undergo reductive elimination through TSc8-c9-OAc, which is only $12.7 \mathrm{kcal} / \mathrm{mol}$ above the reference. The different behavior towards reductive elimination by $\mathbf{c} 7$ and c8-OAc confirms the critical role of ancillary ligands in this step. ${ }^{53}$

The resulting species c9-OAc contains already the diyne product in the palladium coordination sphere. Replacement of the diyne by a new alkyne will regenerate the catalyst and start over the catalytic cycle. The coordination ability of the alkyne and the dialkyne are very similar and the substitution of the dialkyne for a new molecule of the terminal alkyne is almost isoenergetic $(-0.1 \mathrm{kcal} / \mathrm{mol})$, which implies a small equilibrium constant of $\mathrm{K}=1.14$. This indicates a competence of both unsaturated derivatives for coordination to the $\operatorname{Pd}(0)$ center that explains the product inhibition observed.

The validity of this mechanistic proposal was checked by an additional experiment. The presence of hydrogen peroxide was detected in a qualitative experiment by addition of an aliquot of the crude mixture of the catalytic reaction (when the conversion has reached a value of about $50 \%$ ) to a pinkish aqueous solution of $\mathrm{CoSO}_{4} .7 \mathrm{H}_{2} \mathrm{O}$ and $\mathrm{NaHCO}_{3}$, observing the expected color change to green. ${ }^{54}$ Hydrogen peroxide is not necessarily the final product, as palladium complexes can also catalyze the decomposition of $\mathrm{H}_{2} \mathrm{O}_{2}$ to oxygen and water.

The general picture of the alkyne homocoupling catalytic cycle is summarized in Scheme 6. The oxidation is the highest energy step and it is therefore turnover-limiting, which agrees with the strong sensitivity of our experiments to the amount of oxygen present. Moreover, this also agrees with the non-dependence of the reaction rate on the concentration of alkyne or base. The mechanism also provides a rationale for the need of only a catalytic amount of base for the catalytic process (Scheme 6). More base is needed when the precatalyst used is $\mathbf{1}$, as the base is consumed in the precatalytic processes that generate the $\operatorname{Pd}(0)$ active species (Scheme 5 and Figure 4), than when the precatalyst is $\mathbf{5}$, as c4 can be formed by disproportionation without the assistance of a base.

\section{CONCLUSIONS}

An efficient aerobic oxidative homocoupling of alkynes needs of a controlled release of low ligated " $\mathrm{PdPPh}_{3} \mathrm{~L}$ " species. Allylic palladium complexes of formulation $\left[\operatorname{Pd}\left(\eta^{3}-\right.\right.$ $\left.\left.\mathrm{C}_{3} \mathrm{H}_{5}\right)\left(\mathrm{PPh}_{3}\right) \mathrm{X}\right]$ are excellent precursors of those $\mathrm{Pd}(0)$ species in the presence of acetate for several reasons. First, the
Scheme 6. Catalytic cycle for the formation of diynes from alkynes.

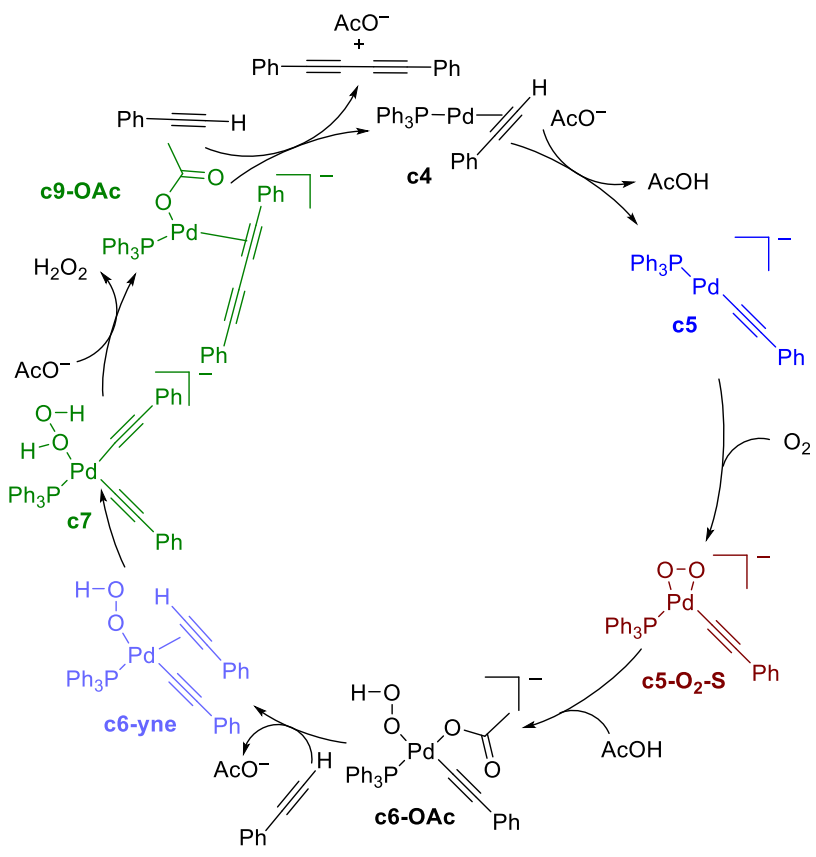

$\eta^{3}$-allylic fragment stabilizes $\mathrm{Pd}$ (II) species and, being a bidentate ligand, few additional ligands on the coordination sphere of the metal are needed. The allyl is not prone to participate in $\mathrm{C}-\mathrm{C}$ coupling reactions (reductive elimination reactions involving this group are slow) but it provides an easy route to $\operatorname{Pd}(0)$ by nucleophilic attack of acetate on the allylic fragment. Moreover, it allows the efficient formation of stable $\mathrm{Pd}(\mathrm{I})$ dimers with an allyl bridge by comproportionation, and this may help to avoid the decomposition of the reactive $\operatorname{Pd}(0)$ species by aggregation, while still being able to release them to the catalytic cycle upon the reverse disproportionation reaction. Thus, $\left[\mathrm{Pd}_{2}\left(\eta^{3}-\mathrm{C}_{3} \mathrm{H}_{5}\right)(\mu-\right.$ $\left.\mathrm{C} \equiv \mathrm{CR})\left(\mathrm{PPh}_{3}\right)_{2}\right] \quad(\mathrm{R}=1$-cyclohexenyl, 7), observed in the catalytic reaction, can be considered as a catalyst resting state out of the operating catalytic cycle. In fact, a $(\mu-$ allyl)Pd(I) dimer can also be used as catalyst precursor for the aerobic formation of diynes from alkynes.

Both the kinetic measurements and DFT calculations point to the oxidation as the rate-limiting step of the reaction. The computational studies, supported by the experimental framework, disclosed some new features. Interestingly, the coordination of $\mathrm{O}_{2}$ occurs on an anionic and dicoordinated $\mathrm{Pd}(0)$ complex $\left[\mathrm{PdPPh}_{3} \mathrm{X}\right]^{-}(\mathrm{X}=$ alkynyl $)$ enabling the oxidation process; a neutral " $\mathrm{PdPPh}_{3} \mathrm{~L}$ " ( $\mathrm{L}=$ alkyne) is not nucleophilic enough to react with oxygen and reduce it. The role of the hydroperoxyl group is important, and it is acting as an internal base to deprotonate the second molecule of alkyne. The reductive elimination, the product forming step, occurs on a Pd(II) bis alkynyl complex, but this is not formed by a double metalation on a $\mathrm{Pd}(\mathrm{II})$ derivative. In fact, the first metalation occurs on $\operatorname{Pd}(0)$ and the second on $\operatorname{Pd}(\mathrm{II})$. Thus, the oxidation of the metal occurs between the substrate activation steps. In contrast to most oxidase-type reactions, the oxidized product formation and the catalyst oxidation cannot be separated.

The origin of diynes as undesired byproducts in Sonogashira couplings, can be explained just by the presence of oxygen, however inadvertently, and the formation of low ligated 
palladium(0) species, an actual intermediate in the cross coupling catalytic cycle. If the synthesis of diynes is the target process, the catalytic system described here is an efficient one and, as far as oxidant and solvent system are concerned, an environmentally friendly synthetic protocol.

\section{ASSOCIATED CONTENT}

\section{Supporting Information}

Experimental details, selected spectra, kinetic data and computational details including cartesian coordinates and calculated potential energies (PDF). The Supporting Information is available free of charge on the ACS Publications website.

\section{AUTHOR INFORMATION}

\section{Corresponding Author}

*albeniz@qi.uva.es (experimental)

*fmaseras@iciq.es (computational)

\section{ACKNOWLEDGMENT}

ACA thanks financial support from the Spanish MINECO (SGPI, grant CTQ2016-80913-P, BES-2014-067770 fellowship to AT). FM thanks financial support from the CERCA Programme (Generalitat de Catalunya) and from the Spanish MINECO (CTQ2017-87792-R and Severo Ochoa Excellence Accreditation 2014-2018, SEV-2013-0319). IFA acknowledges a fellowship from the ICIQ-Severo Ochoa programme (SVP2014-068662). This collaborative work has benefited from the Red de Excelencia CTQ2016-81923-REDC (MINECO).

\section{REFERENCES}

(1) a) Stahl, S. S. Palladium Oxidase Catalysis: Selective Oxidation of Organic Chemicals by Direct Dioxygen-Coupled Turnover. Angew. Chem. Int. Ed. 2004, 43, 3400-3420. b) Stahl, S. S. Palladium-Catalyzed Oxidation of Organic Chemicals with $\mathrm{O}_{2}$. Science 2005, 309, 1824-1826.

(2) a) ten Brink, G. -J.; Arends, I. W. C. E.; Sheldon, R. A. Green, Catalytic Oxidation of Alcohols in Water. Science, 2000, 287, 1636-1639. b) Jensen, D. R. Pugsley, J. S.; Sigman, M. S. Palladium-Catalyzed Enantioselective Oxidations of Alcohols Using Molecular Oxygen. J. Am. Chem. Soc. 2001, 123, 7475-7476. c) Muzart, J. Palladium-catalysed oxidation of primary and secondary alcohols. Tetrahedron 2003, 59, 5789-5816 Uemura, S. Novel palladium catalytic systems for organic transformations. Synlett, 2004, 2, 201-216. e) Sigman, M. S.; Jensen, D. R. Ligand-Modulated Palladium-Catalyzed Aerobic Alcohol Oxidations. Acc. Chem. Res. 2006, 39, 221-229.

(3) a) McDonald, R. I.; Liu, G.; Stahl, S. S. Palladium(II)Catalyzed Alkene Functionalization via Nucleopalladation: Stereochemical Pathways and Enantioselective Catalytic Applications. Chem. Rev. 2011, 111, 2981-3019. b) Mann, S. E.; Benhamou, L.; Sheppard, T. D. Palladium(II)-Catalysed Oxidation of Alkenes. Synthesis, 2015, 47, 3079-3117.

(4) Liu, Q.; Zhang, H.; Lei, A. Oxidative Carbonylation Reactions: Organometallic Compounds (R-M) or Hydrocarbons (R-H) as Nuclephiles. Angew. Chem. Int. Ed. 2011, 50, 10788-10799.

(5) a) Wu, W.; Jiang, H. Palladium-Catalyzed Oxidation of Unsaturated Hydrocarbons Using Molecular Oxygen. Acc. Chem. Res. 2012, 45, 1736-1748. b) Deng, Y.; Persson, A. K.; Bäckvall, J. -E. Palladium-Catalyzed Oxidative Carbocyclizations. Chem. Eur. J. 2012, 18, 11498-11523.

(6) a) Chen, X.; Engle, K. M.; Wang, D. -H.; Yu, J. -Q. Palladium(II)-Catalyzed C-H Activation/C-C Cross-Coupling Reactions:
Versatility and Practicality. Angew. Chem. Int. Ed. 2009, 48, 50945115. b) Izawa, Y.; Pun, D.; Stahl, S. S. Palladium-Catalyzed Aerobic Dehydrogenation of Substituted Cyclohexanones to Phenols. Science, 2011, 333, 209-213. c) Gigant, N.; Bäckvall, J. -E. Synthesis of Conjugated Dienes via a Biomimetic Aerobic Oxidative Coupling of Two Cvinyl H Bonds, Chem. Eur. J. 2013, 19, 10799-10803. d) Iosub, A. V.; Stahl, S. S. Palladium-Catalyzed Aerobic Dehydrogenation of Cyclic Hydrocarbons for the Synthesis of Substituted Aromatics and Other Unsaturated Products. ACS. Catal. 2016, 6, 8201-8213. e) Xiao, K. -J.; Chu, L.; Yu, J. -Q. Enantioselective $\mathrm{C}$-H Olefination of $\alpha$-Hydroxy and $\alpha$-Amino Phenylacetic Acids by Kinetic Resolution. Angew. Chem. Int. Ed. 2016, 55, 2856-2860. f) Yang, Y.; Lan, J.; You, J. Oxidative C-H/C$\mathrm{H}$ Coupling Reactions between Two (Hetero)arenes. Chem. Rev. 2017, 117, 8787-8863.

(7) a) Gligorich, K. M.; Sigman, M. S. Recent advancements and challenges of palladium ${ }^{\mathrm{II}}$-catalyzed oxidation reactions with molecular oxygen as the sole oxidant. Chem. Commun. 2009, 3854-3867. b) Campbell, A. N.; Stahl, S. S. Overcoming the "Oxidant Problem": Strategies to Use $\mathrm{O}_{2}$ as the Oxidant in Organometallic C-H Oxidation Reactions Catalyzed by $\mathrm{Pd}$ (and $\mathrm{Cu}$ ). Acc. Chem. Res. 2012, 45, 851-863. c) Shi, Z.; Zhang, C.; Tang, C.; Jiao, N. Recent Advances in transition-metal catalyzed reactions using molecular oxygen as the oxidant. Chem. Soc. Rev., 2012, 41, 33813430. d) Wang, D.; Weinstein, A. B.; White, P. B.; Stahl, S. S. Ligand-Promoted Palladium-Catalyzed Aerobic Oxidation Reactions. Chem. Rev. 2018, 118, 2636-2679.

(8) Steinhoff, B. A.; Fix, S. R.; Stahl, S. S. Mechanistic Study of Alcohol Oxidation by the $\mathrm{Pd}(\mathrm{OAc})_{2} / \mathrm{O}_{2} / \mathrm{DMSO}$ Catalyst System and Implications for the Development of Improved Aerobic Oxidation Catalysts. J. Am. Chem. Soc. 2002, 124, 766-767.

(9) Scheuermann, M. L.; Goldberg, K. I. Reactions of Pd and Pt Complexes with Molecular Oxygen. Chem. Eur. J. 2014, 20, 1455614568.

(10) a) Wilke, G.; Schott, H.; Heimbach, P. Oxygen Complexes of Zerovalent Nickel, Palladium and Platinum. Angew. Chem. Int. Ed. Engl. 1967, 6, 92-93. b) C. J. Nyman, C. J.; Wymore, C. E.; Wilkinson, G. Reactions of Tris(triphenylphosphine)platinum( $(0)$ and Tetrakis(tri-phenylphosphine)palladium(0) with Oxygen and Carbon Dioxide J. Chem. Soc. A, 1968, 561-563.

(11) a) Stahl, S. S.; Thorman, J. L.; Nelson, R. C.; Kozee, M. A. Oxygenation of Nitrogen-Coordinated Palladium(0): Synthetic, Structural, and Mechanistic Studies and Implications for Aerobic Oxidation Catalysis. J. Am. Chem. Soc. 2001, 123, 7188-7189. b) C. R. Landis, C. M. Morales, S. S. Stahl. Insights into the SpinForbidden Reaction between $\mathrm{L}_{2} \mathrm{Pd}^{0}$ and Molecular Oxygen. J. Am. Chem. Soc. 2004, 126, 16302-16303. c) Popp, B. V.; Wendlandt, J. E.; Landis, C. R.; Stahl, S. S. Reaction of Molecular Oxygen with an NHC-Coordinated $\mathrm{Pd}^{0}$ Complex: Computational Insights and Experimental Implications. Angew. Chem. Int. Ed. 2007, 46, $601-$ 604.

(12) Konnick, M. M.; Guzei, I. A.; Stahl, S. S. Characterization of Peroxo and Hydroperoxo Intermediates in the Aerobic Oxidation of $\mathrm{N}$-Heterocyclic-Carbene-Coordinated Palladium(0). J. Am. Chem. Soc. 2004, 126, 10212-10213.

(13) a) Konnick, M. M; Gandhi, B. A.; Guzei, I. A.; Stahl, S. S. Reaction of Molecular Oxygen with a $\mathrm{Pd}^{\mathrm{II}}$-Hydride To Produce a $\mathrm{Pd}^{\mathrm{II}}$-Hydroperoxide: Acid Catalysis and Implications for PdCatalyzed Aerobic Oxidation Reactions. Angew. Chem. Int. Ed. 2006, 45, 2904-2907. b) Popp, B. V.; Stahl, S. S. Insertion of Molecular Oxygen into a Palladium-Hydride Bond: Computational Evidence for Two Nearly Isoenergetic Pathways. J. Am. Chem. Soc. 2007, 129, 4410-4422. c) Konnick, M. M.; Stahl, S. S. Reaction of Molecular Oxygen with a $\mathrm{Pd}^{\mathrm{II}}$-Hydride To Produce a $\mathrm{Pd}^{\mathrm{II}}$ Hydroperoxide: Experimental Evidence for an HX-ReductiveElimination Pathway. J. Am. Chem. Soc. 2008, 130, 5753-5762. d) Popp, B. V.; Stahl, S. S. Mechanism of $\mathrm{Pd}(\mathrm{OAc})_{2} /$ Pyridine Catalyst Reoxidation by $\mathrm{O}_{2}$ : Influence of Labile Monodentate Ligands and 
Identification of a Biomimetic Mechanism for $\mathrm{O}_{2}$ Activation. Chem. Eur. J. 2009, 15, 2915-2922.

(14) a) Keith, J. M.; Goddard III, W. A.; Oxgaard, J. PdMediated Activation of Molecular Oxygen: $\operatorname{Pd}(0)$ versus Direct Insertion. J. Am. Chem. Soc. 2007, 129, 10361-10369. b) Decharin, N.; Popp, B. V.; Stahl, S. S. Reaction of $\mathrm{O}_{2}$ with [(-)Sparteine] $\mathrm{Pd}(\mathrm{H}) \mathrm{Cl}$ : Evidence for an Intramolecular [H-L $]^{+}$"Reductive Elimination" Pathway. J. Am. Chem. Soc. 2011, 133, 1326813271. c) Keith, J. M.; Goddard III, W. A. Chelating Base Effects in Palladium-Mediated Activation of Molecular Oxygen. Organometallics 2012, 31, 545-552.

(15) a) Denney, M. C.; Smythe, N. A.; Cetto, K. L.; Kemp, R. A.; Goldberg, K. I. Insertion of Molecular Oxygen into a Palladium(II) Hydride Bond. J. Am. Chem. Soc. 2006, 128, 2508-2509. b) Keith, J. M.; Muller, R. P.; Kemp, R. A.; Goldberg, K. I.; Goddard III, W. A.; Oxgaard, J. Mechanism of Direct Molecular Oxygen Insertion in a Palladium(II)-Hydride Bond. Inorg. Chem. 2006, 45, 9631-9633.

(16) a) Keith, J. M.; Goddard III, W. A. Mechanism for Activation of Molecular Oxygen by cis- and trans-(Pyridine) ${ }_{2} \mathrm{Pd}(\mathrm{OAc}) \mathrm{H}$ : $\mathrm{Pd}^{0}$ versus Direct Insertion. J. Am. Chem. Soc. 2009, 131, 14161425. b) Konnick, M. M; Decharin, N; Popp, B. V.; Stahl, S. S. O insertion into a palladium(II)-hydride bond: Observation of mechanistic crossover between HX-reductive-elimination and hydrogenatom-abstraction pathways. Chem. Sci. 2011, 2, 326-330.

(17) a) Cai, X.; Majumdar, S.; Fortman, G. C.; Cazin, C. S. J.; Slawin, A. M. Z.; Lhermitte, C.; Prabhakar, R.; Germain, M. E.; Palluccio, T.; Nolan, S. P.; Rybak-Akimova, E. V.; Temprado, M.; Captain, B.; Hoff, C.D. Oxygen Binding to $\left[\mathrm{Pd}(\mathrm{L})\left(\mathrm{L}^{\prime}\right)\right](\mathrm{L}=\mathrm{NHC}$, $\mathrm{L}^{\prime}=\mathrm{NHC}$ or $\mathrm{PR}_{3}, \mathrm{NHC}=\mathrm{N}$-Heterocyclic Carbene). Synthesis and Structure of a Paramagnetic trans-[Pd(NHC $\left.)_{2}\left(\eta^{1}-\mathrm{O}_{2}\right)_{2}\right]$ Complex. $J$. Am. Chem. Soc. 2011, 133, 1290-1293. b) Scheuermann, M. L.; Boyce, D. W.; Grice, K. A.; Kaminsky, W.; Stoll, S.; Tolman, W. B.; Swang, O.; Goldberg, K. I. Oxygen-Promoted C-H Bond Activation at Palladium. Angew. Chem. Int. Ed. 2014, 53, 6492-6495.

(18) a) Siemsen, P.; Livingston, R. C.; Diederich, F. Acetylenic Coupling: A Powerful Tool in Molecular Construction. Angew. Chem. Int. Ed. 2000, 39, 2632-2657. b) Stefani, H. A.; Guarezemini, A. S.; Cella, R. Homocoupling reactions of alkynes, alkenes and alkyl compounds. Tetrahedron, 2010, 66, 7871-7918. c) Alonso, F.; Yus, M. Heterogeneous Catalytic Homocoupling of Terminal Alkynes. ACS Catal. 2012, 2, 1441-1451.

(19) Jover J.; Spuhler, P.; Zhao, L.; McArdle, C.; Maseras, F. Toward a mechanistic understanding of oxidative homocoupling: the Glaser-Hay reaction. Catal. Sci. Technol. 2014, 4, 4200-4209.

(20) a) Ye, C.; Xiao, J. -C.; Twamley, B.; LaLonde, A. D.; Norton, M. G.; Shreeve, J. M. Basic Ionic Liquids: Facile Solvents for Carbon-Carbon Bond Formation Reactions and Ready Access to Palladium Nanoparticles. Eur. J. Org. Chem. 2007, 30, 5095-5100. b) Atobe, S.; Sonoda, M.; Suzuki, Y.; Yamamoto, T.; Masuno, H.; Shinohara, H.; Ogawa, A. Palladium-catalyzed oxidative homocoupling reaction of terminal acetylenes using trans-bidentatable 1-(2pyridylethynyl)-2-(2-thienylethynyl)-benzene. Res. Chem. Intermed. 2013, 39, 359-370. c) Chen, L.; Lemma, B. E.; Rich, J. S.; Mack, J. Freedom: a copper-free, oxidant-free and solvent-free palladium catalysed homocoupling reaction. Green Chem. 2014, 16, 11011103.

(21) a) Alper, H.; Saldana-Maldonado, M. Palladium-Catalyzed Alkyne-Oxalate Ester Reaction. A formal Carbon-Carbon Bond Cleavage Process. Organometallics, 1989, 8, 1124-1125. b) Liu, Q.; Burton, D. J. A Facile Synthesis of Diynes. Tetrahedron Lett. 1997, $38,4371-4374$.

(22) Sameera, W. M. C.; Maseras, F. Transition metal catalysis by density functional theory and density functional theory/molecular mechanics. WIREs Comput. Mol. Sci. 2012, 2, 375-385.

(23) a) García-Melchor, M.; Braga, A. A. C.; Lledós, A.; Ujaque, G.; Maseras, F. Computational Perspective on Pd-Catalyzed C-C Cross-Coupling Reaction Mechanisms. Acc. Chem. Res. 2013, 46, 2626-2634. b) Sperger, T.; Sanhueza, I. A.; Kalvet, I.; Schoenebeck, F. Computational Studies of Synthetically Relevant Homogeneous
Organometallic Catalysis Involving $\mathrm{Ni}, \mathrm{Pd}$, Ir, and $\mathrm{Rh}$ : An Overview of Commonly Employed DFT Methods and Mechanistic Insights. Chem. Rev. 2015, 115, 9532-9586.

(24) a) Funes-Ardoiz, I.; Maseras, F. Cooperative Reductive Elimination: The Missing Piece in the Oxidative-Coupling Mechanistic Puzzle. Angew. Chem. Int. Ed. 2016, 55, 2764-2767. b) Funes-Ardoiz, I.; Maseras, F. Oxidative Coupling Mechanisms: Current State of Understanding. ACS Catal. 2018, 8, 1161-1172. c) Funes-Ardoiz, I.; Maseras, F. Computational Characterization of the Mechanism for the Oxidative Coupling of Benzoic Acid and Alkynes by $\mathrm{Rh} / \mathrm{Cu}$ and $\mathrm{Rh} / \mathrm{Ag}$ Systems. Chem. Eur. J. 2018, in press, DOI: $10.1002 /$ chem.201800627.

(25) a) Meana, I.; Albéniz, A. C.; Espinet P. Selective Green Coupling of Alkynyltins and Allylic Halides to Trienynes via a Tandem Double Stille Reaction. Adv. Synth. Catal. 2010, 352, 2887 2891. b) Meana, I.; Albéniz, A. C.; Espinet P. Heterometallic Complexes by Transmetalation of Alkynyl Groups from Copper or Silver to Allyl Palladium Complexes: Demetalation Studies and Alkynyl Homocoupling. Organometallics, 2014, 33, 1-7.

(26) Steinhoff, B. A. Stahl, S. S. Mechanism of $\mathrm{Pd}(\mathrm{OAc})_{2} / \mathrm{DMSO}-$ Catalyzed Aerobic Alcohol Oxidation: MassTransfer-Limitation Effects and Catalyst Decomposition Pathways. J. Am. Chem. Soc. 2006, 128, 4348-4355.

(27) Vlassa, M.; Ciocan-Tarta, I.; Margineanu, F.; Oprean, I. Synthesis of Diynes by Phase Transfer Catalysis in the Presence of a $\operatorname{Pd}(0)$ Catalyst. Tetrahedron, 1996, 52, 1337-1342.

(28) Yamamoto, Y.; Nagata, A.; Nagata, H.; Ando, A.; Arikawa, Y.; Tatsumi, K.; Itoh, K. Palladium(0)-Catalyzed Intramolecular $[2+2+2]$ Alkyne Cyclotrimerizations with Electron-Deficient Diynes and Triynes. Chem. Eur. J. 2003, 9, 2469-2483.

(29) a) Dietl, H.; Reinheimer, H.; Moffat, J. Maitlis, P. M. Reactions of Acetylenes with Noble-Metal Halides. VIII. The Palladium Chloride Catalyzed Trimerization of 2-Butyne and 1-Phenyl-1propyne. J. Am. Chem. Soc. 1970, 82, 2276-2285. b) Maitlis, P. M. The Palladium(II)-Induced Oligomerization of Acetylenes: An Organometallic Detective Story. Acc. Chem. Res. 1976, 9, 93-99.

(30) Sato, T.; Hamada, Y.; Sumikawa, M.; Araki, S.; Yamamoto, H. Solubility of Oxygen in Organic Solvents and Calculation of the Hansen Solubility Parameters of Oxygen. Ind. Eng. Chem. Res. 2014, 53, 19331-19337.

(31) Gómez-Gallego, M.; Sierra, M. A. Kinetic Isotope Effects in the Study of Organometallic Reaction Mechanisms. Chem. Rev. 2011, 111, 4857-4963.

(32) Simmons, E. M.; Hartwig, J. F. On the Interpretation of Deuterium Kinetic Isotope Effects in C-H Bond Functionalizations by Transition-Metal Complexes. Angew. Chem. Int. Ed. 2012, 51, 3066-3072.

(33) $3-4 \%$ of $\mathrm{OPPh}_{3}$ was detected in some experiments.

(34) a) Yamamoto, T.; Akimoto, M.; Osamu, S.; Yamamoto, A. Interaction of Palladium(0) Complexes with Allylic Acetates, Allyl Ethers, Allyl Phenyl Chalcogenides, Allylic Alcohols, and Allylamines. Oxidative Addition, Condensation, Disproportionation, and $\pi$-Complex Formation. Organometallics 1986, 5, 1559-1567. b) Hazari, N.; Hruszkewycz, D. P. Dinuclear $\mathrm{Pd}^{\mathrm{I}}$ complexes with bridging allyl and related ligands. Chem. Soc. Rev. 2016, 45, 28712899.

(35) a) Wada, M.; Koyama, Y. Comparison of organo-Nickel(II), -Palladium(II) and -Platinum(II) complexes. I. Preparation and acidities of cationic methyl(mehoxy)carbene complexes. J. Organomet. Chem. 1980, 201, 477-491. b) Bacchi, A.; Carcelli, M.; Costa, M.; Fochi, A.; Monici, C.; Pelagatti, P.; Pelizzi, C.; Pelizzi, G.; Sanjuan Roca, L. M. Stable alkynyl palladium(II) and nickel(II) complexes with terdentate PNO and PNN hydrazone ligands. $J$. Organomet. Chem. 2000, 593-594, 180-191. c) Kohyama, Y.; Murase, T.; Fujita, M. Metal-Organic Proximity in a Synthetic Pocket. J. Am. Chem. Soc. 2014, 136, 2966-2969.

(36) For examples of $\mathrm{Pd}(\mathrm{I})$ complexes with bridging alkynyl groups: a) Murahashi, T.; Otani, T.; Okuno, T.; Kurosawa, H. Coupling of Alkynes on a Pd-Pd Bond to Generate an Electrophilic $\mu$ Butenediylidene Moiety. Angew. Chem. Int. Ed. 2000, 39, 537-540. 
b) Krause, J.; Goddard R.; Mynott, R.; Pörschke, K-R. A Dinuclear Palladium(I) Ethynyl Complex: Synthesis, Structure, and Dynamics. Organometallics 2001, 20, 1992-1999.

(37) Hruszkewycz, D.P.; Balcells, D.; Guard, L.M.; Hazari, N.; Tilset, M. Insight into the Efficiency of Cinnamyl-Supported Precatalysts for the Suzuki-Miyaura Reaction: Observation of Pd(I) Dimers with Bridging Allyl Ligands During Catalysis. J. Am. Chem. Soc. 2014, 136, 7300-7316.

(38) a) Amatore, C.; Jutand, A.; Meyer, G.; Mottier, L. Evidence of the Reversible Formation of Cationic $\pi$-Allylpalladium(II) Complexes in the Oxidative Addition of Allylic Acetates to Palladium(0) Complexes. Chem. Eur. J. 1999, 5, 466-473. b) Fristrup, P.; Ahlquist, M.; Tanner, D.; Norrby, P.-O. On the Nature of the Intermediates and the Role of Chloride Ions in Pd-Catalyzed Allylic Alkylations: Added Insight from Density Funcional Theory. J. Phys. Chem. A 2008, 112, 12862-12867.

(39) Barder, T. E. Synthesis, Structural, and Electron Topographical Analyses of a Dialkylbiaryl Phosphine/Arene-Ligated Palladium(I) Dimer: Enhanced Reactivity in Suzuki-Miyaura Coupling Reactions. J. Am. Chem. Soc. 2006, 128, 898-904.

(40) a) Christmann, U.; Pantazis, D. A.; Benet-Buchholz, J.; McGrady, J. E.; Maseras, F.; Vilar, R. Experimental and Theoretical Investigations of New Dinuclear Palladium Complexes as Precatalysts for the Amination of Aryl Chlorides. J. Am. Chem. Soc. 2006, 128, 6376-6390. b) Hill, L. L.; Crowell, J. L.; Tutwiler, S. L.; Massie, N. L.; Hines, C. C.; Griffin, S. T.; Rogers, R. D.; Shaughnessy, K. H.; Grasa, G. A.; Johansson Seechurn, C. C. C; Li, H.; Colacot, T. J.; Chou J.; Woltermann, C. J. Synthesis and X-ray Structure Determination of Highly Active Pd(II), Pd(I), and Pd(0) Complexes of $\mathrm{Di}$ (tert-butyl)neopentylphosphine (DTBNpP) in the Arylation of Amines and Ketones. J. Org. Chem. 2010, 75, 6477-6488.

(41) a) Proutiere, F.; Aufiero, M.; Schoenebeckisepi, F. Reactivity and Stability of Dinuclear Pd(I) Complexes: Studies on the Active Catalytic Species, Insights into Precatalyst Activation and Deactivation, and Application in Highly Selective Cross-Coupling Reactions. J. Am. Chem. Soc. 2012, 134, 606-612. b) Aufiero, M.; Scattolin, T.; Proutière, F.; Schoenebeck, F. Air-Stable Dinuclear IodineBridged Pd(I) Complex - Catalyst, Precursor, or Parasite? The Additive Decides. Systematic Nucleophile-Activity Study and Application as Precatalyst in Cross-Coupling. Organometallics 2015, 34, 5191-5195. c) Kalvet, I.; Sperger, T.; Scattolin, T.; Magnin, G.; Schoenebeck F. Palladium(I) Dimer Enabled Extremely Rapid and Chemoselective Alkylation of Aryl Bromides over Triflates and Chlorides in Air. Angew. Chem. Int. Ed. 2017, 56, 7078 7082 .

(42) Finke, A. D.; Elleby, E. C.; Boyd, M. J.; Weissman, H.; Moore, J. S. Zinc Chloride-Promoted Aryl Bromide-Alkyne CrossCoupling Reactions at Room Temperature. J. Org. Chem. 2009, 74, 8897-8900.

(43) Oldenhof, S.; Lutz, M.; de Bruin, B.; van der Vlugt, J. I.; Reek, J. N. H. Well-Defined BisMETAMORPhos Pd'-Pd Complex: Synthesis, Structural Characterization, and Reactivity. Organometallics 2014, 33, 7293-7298.

(44) Jaworski, J. N.; McCann, S. D.; Guzei, I. A.; Stahl, S. S. Detection of Palladium(I) in Aerobic Oxidation Catalysis. Angew. Chem. Int. Ed. 2017, 56, 3605-3610.

(45) Weissman, H.; Shimon, L. J. W.; Milstein, D. Unsaturated $\operatorname{Pd}(0), \operatorname{Pd}(\mathrm{I})$, and $\mathrm{Pd}(\mathrm{II})$ Complexes of a New Methoxy-Substituted Benzyl Phosphine. Aryl-X $(\mathrm{X}=\mathrm{Cl}, \mathrm{I})$ Oxidative Addition, $\mathrm{C}-\mathrm{O}$ Cleavage, and Suzuki-Miyaura Coupling of Aryl Chlorides. Organometallics 2004, 23, 3931-3940.

(46) Pank, V.; Müller, H-P.; Nast, R. Komplexe von Palladium(II)-acetyliden mit 1,2-Bis(diphenylphosphino)ethan. Chem. Ber. 1978, 111, 1627-1631.

(47) a) Becke, A. D. Density-functional thermochemistry. III. The role of exact exchange. J. Chem. Phys. 1993, 98, 5648-5652. b) Lee, C.; Yang, W.; Parr, R. G. Development of the Colle-Salvetti correlation-energy formula into a functional of the electron density. Phys. Rev. B.: Condens. Mater. 1988, 37, 785-789. c) Stephens, P. J.; Devlin, F. J.; Chabalowski, C. F.; Frisch, M. J. Ab Initio Calcula- tion of Vibrational Absorption and Circular Dichroism Spectra Using Density Functional Force Fields. J. Phys. Chem. 1994, 98, 11623-11627.

(48) Grimme, S.; Antony, J.; Ehrlich, S.; Krieg, H. A consistent and accurate $\mathrm{ab}$ initio parametrization of density functional dispersion correction (DFT-D) for the 94 elements H-Pu. J. Chem. Phys. 2010, 132, 154104-154119.

(49) Marenich, A. V.; Cramer, C. J.; Truhlar, D. G. Universal Solvation Model Based on Solute Electron Density and on a Continuum Model of the Solvent Defined by the Bulk Dielectric Constant and Atomic Surface Tensions. J. Phys. Chem. B 2009, 113, 6378-6396.

(50) Álvarez-Moreno, M.; de Graaf, C.; Lopez, N.; Maseras, F.; Poblet, J. M.; Bo, C. Managing the Computational Chemistry Big Data Problem: The ioChem-BD Platform. J. Chem. Inf. Model. 2015, 55, 95.

(51) Amatore, C.; Jutand, A. Anionic Pd(0) and Pd(II) Intermediates in Palladium-Catalyzed Heck and Cross-Coupling Reactions. Acc. Chem. Res. 2000, 33, 314- 321.

(52) Harvey, J. N.; Aschi, M.; Schwarz, H.; Koch, W. The singlet and triplet states of phenyl cation. A hybrid approach for locating minimum energy crossing points between non-interacting potential energy surfaces. Theor. Chem. Acc. 1998, 99, 95-99.

(53) Pérez-Rodríguez, M.; Braga, A. A. C.; García-Melchor, M.; Pérez-Temprano, M. H.; Casares, J. A.; Ujaque, G.; de Lera, A. R.; Álvarez, R.; Maseras, F.; Espinet, P. C-C Reductive Elimination in Palladium Complexes, and the Role of Coupling Additives. A DFT Study Supported by Experiment. J. Am. Chem. Soc. 2009, 131, 3650-3657.

(54) Belhateche, D.; Symons, J. M. Using Cobalt-Ultraviolet Spectrophotometry to Measure Hydrogen Peroxide Concentration in Organically Laden Groundwaters. Journal AWWA, 1991, 83, 70-73. 


\section{Graphics for the Table of contents}

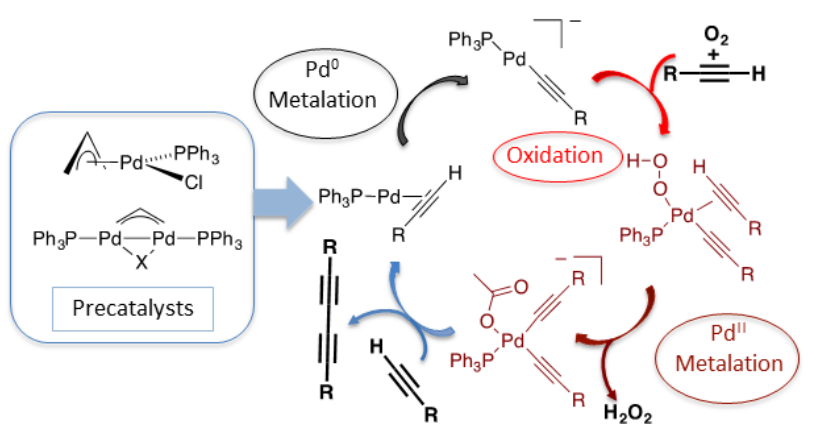

